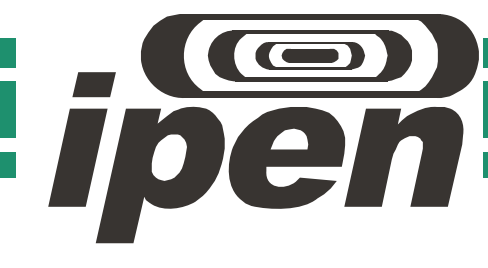

AUTARQUIA ASSOCIADA À UNIVERSIDADE DE SÃO PAULO

Desenvolvimento de um programa computacional para gerenciamento de banco de dados de material nuclear

Julio Benedito Marin Tondin

Dissertação apresentada como parte dos requisitos para obtenção do Grau de Mestre em Ciências na Área de Tecnologia Nuclear - Aplicações

Orientador:

Prof. Dr. Tufic Madi Filho 


\section{AGRADECIMENTOS}

Agradeço

Em primeiro lugar a Deus, que ilumina e orienta todos os meus passos.

Aos meus pais, Julio e Catharina, que construíram a base de quem sou hoje.

À Wania, minha esposa, e aos meus filhos Fernanda e André, que me estimulam a ser sempre melhor.

Ao Dr. Tufic Madi Filho, estimado orientador da dissertação de mestrado, pessoa que admiro e respeito.

Aos meus amigos em especial a equipe de operação do Reator IEA-R1 pela ajuda durante a elaboração deste trabalho. 


\title{
DESENVOLVIMENTO DE PROGRAMA COMPUTACIONAL PARA GERENCIAMENTO DE BANCO DE DADOS DE MATERIAL NUCLEAR.
}

\section{JULIO BENEDITO MARIN TONDIN}

\begin{abstract}
RESUMO
Em instalações nucleares o controle do material nuclear é uma das atividades da maior importância. A Comissão Nacional de Energia Nuclear (CNEN) e a Agencia Internacional de Energia Atomica (AIEA) quando de suas inspeções rotineiras tem os dados fornecidos como um fator de segurança. Ter um sistema de controle de material nuclear que permita a qualquer momento reportar a quantidade e a localização dos diversos itens a serem inspecionados é um fator de primordial importância nos dias de hoje.

Neste trabalho objetivou-se aprimorar um sistema já existente utilizando para seu desenvolvimento uma plataforma mais amigável através da linguagem de programação VisualBasic (Microsoft Corporation) para facilitar a equipe de operação do Reator IEA-R1 o fornecimento de dados que possibilitem o melhor controle dos materiais nucleares do Reator IEA-R1. Esses dados tem permitido o desenvolvimento de trabalhos a serem apresentados em congressos nacionais ou internacionais bem como em dissertações de mestrado ou teses de doutorado. $O$ programa foi desenvolvido para atender as exigências das normas de salvaguarda da CNEN e da AIEA, mas suas funções podem ser ampliadas conforme as necessidades futuras. Este sistema poderá ser utilizado em outros reatores que por ventura sejam contruidos no pais, pois é bem pratico e sua utilização permite um um controle efetivo sobre o material nuclear da instalação.
\end{abstract}




\title{
SOFTWARE DEVELOPMENT FOR MANAGING NUCLEAR MATERIAL DATABASE
}

\section{JULIO BENEDITO MARIN TONDIN}

\begin{abstract}
In nuclear facilities, the nuclear material control is one of the most important activities. The National Commission of Nuclear Energy (CNEN) and the International Atomic Energy Agency (IAEA), when inspecting routinely, regards the data provided as a major safety factor. Having a control system of nuclear material that allows the amount and location of the various items to be inspected, at any time, is a key factor today.

The objective of this work was to enhance the existing system using a more friendly platform of development, through the VisualBasic programming language (Microsoft Corporation), to facilitate the operation team of the reactor IEA-R1 Reactor tasks, providing data that enable a better and prompter control of the IEAR1 nuclear material. These data have allowed the development of papers presented at national and international conferences and the development of master's dissertations and doctorate theses.

The software object of this study was designed to meet the requirements of the CNEN and the IAEA safeguard rules, but its functions may be expanded in accordance with future needs. The program developed can be used in other reactors to be built in the country, since it is very practical and allows an effective control of the nuclear material in the facilities.
\end{abstract}




\section{SUMÁRIO}

\section{Pagina}

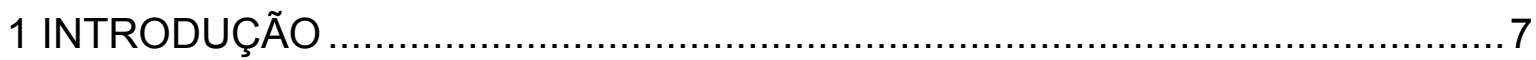

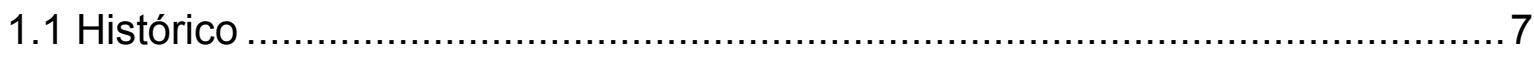

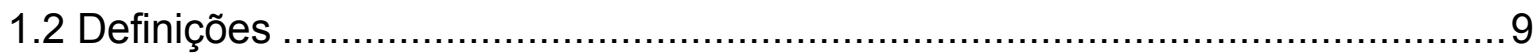

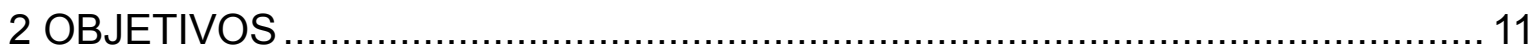

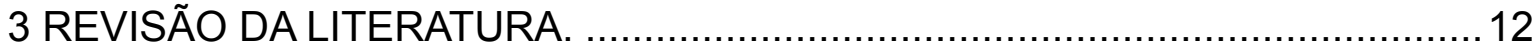

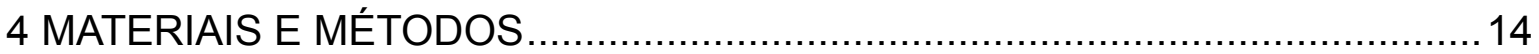

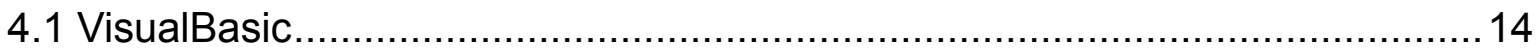

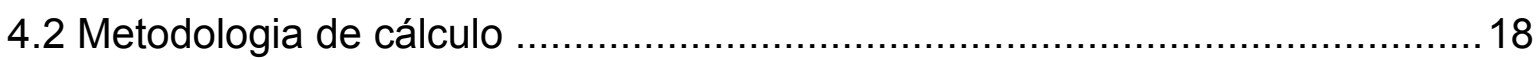

4.2.1 Fator de conversão da fissão em energia ........................................ 18

4.2.2 Fluxo de nêutrons térmicos médio na posição ........................................19

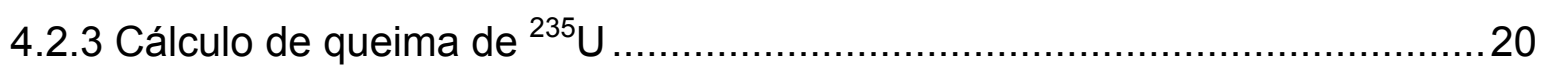

4.2.4 Cálculo da queima de Urânio total ....................................................... 21

4.2.5 Formação de Plutônio ................................................................. 21

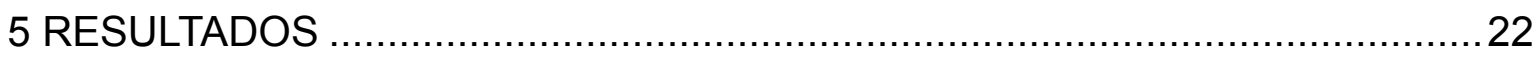

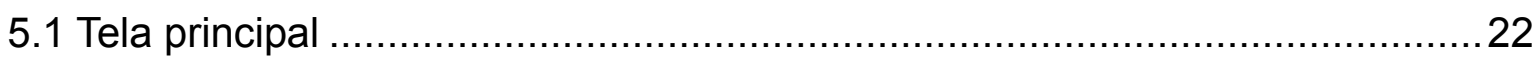

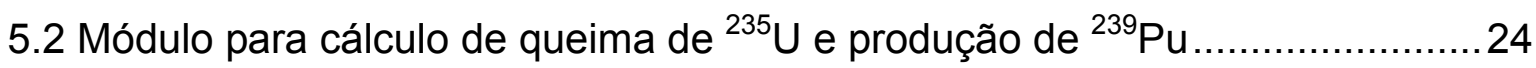

5.3 Editor de arquivos ........................................................................ 28

5.4 Queima por configuração ............................................................... 31

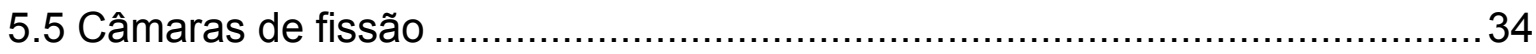

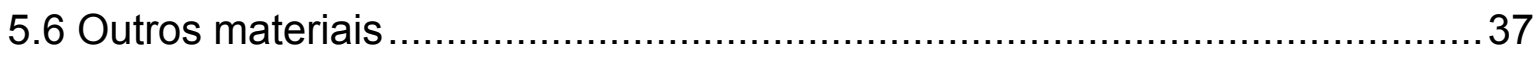

6 - ANÁLISE E DISCUSSÃO DE RESULTADOS ....................................... 40

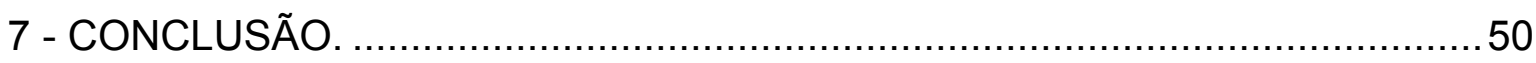

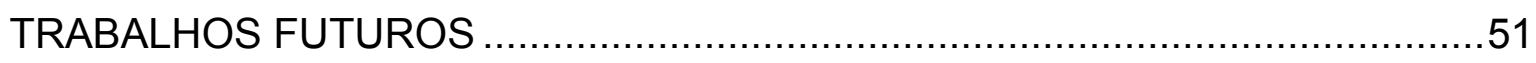

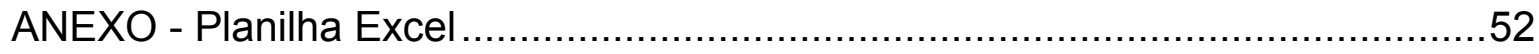

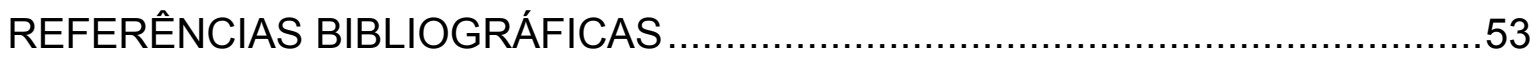




\section{LISTA DE TABELAS}

Tabela 1: Função dos Botões do Programa .................................................. 22

Tabela 2: Massa Final dos Elementos Combustíveis ......................................40

Tabela 3: Queima dos Elementos Combustíveis ...........................................41

Tabela 4: Diferença de Queima dos Elementos Combustíveis com relação ao Programa Atual....................................................................... 41

Tabela 5: Cálculo da Queima de ${ }^{235} \mathrm{U}$ na Configuração 218 ..............................41

Tabela 6: Cálculo da Queima de ${ }^{235} \mathrm{U}$ na Configuração 219 ............................42

Tabela 7: Queima do Elemento Combustível 193 ........................................43

Tabela 8: Queima do Elemento Combustível 194 .........................................44

Tabela 9: Queima do Elemento Combustível 195 ............................................45 


\section{LISTA DE FIGURAS}

Figura 1: Configuração básica do núcleo do reator..................................... 8

Figura 2: Tela inicial do VisualBasic $\quad 15$

Figura 3: Tela inicial do módulo de programação do VisualBasic 16

Figura 4: Tela do módulo de programação do VisualBasic .............................17

Figura 5: Esquema de uma célula básica utilizada no programa TWODB...........19

Figura 6: Tela principal apresentando os botões de funções do programa ...........23

Figura 7: Tela do módulo para cálculo de queima de ${ }^{235} \mathrm{U}$ e produção de ${ }^{239} \mathrm{Pu} \ldots 25$

Figura 8: Tela do módulo para cálculo de queima de ${ }^{235} \mathrm{U}$ e produção de ${ }^{239} \mathrm{Pu}$

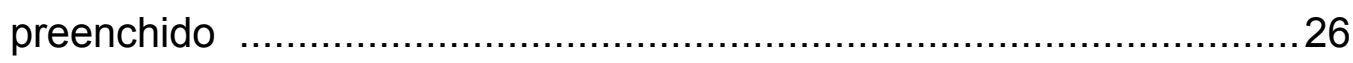

Figura 9: Formulário gerado pelo módulo para cálculo de queima de ${ }^{235} \mathrm{U}$ e

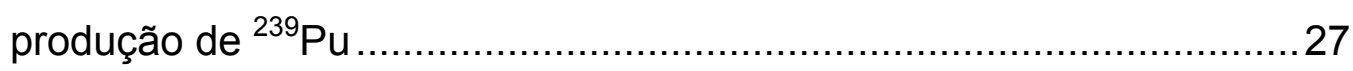

Figura 10: Tela do módulo para edição de arquivo ....................................29

Figura 11: Tela do módulo para edição de arquivo preenchido .......................... 30

Figura 12: Tela do módulo para cálculo de queima individual na configuração......32

Figura 13: Tela do módulo para cálculo de queima individual na configuração preenchido. ................................................................... 33

Figura 14: Tela do módulo com dados das câmaras de fissão........................... 35

Figura 15: Tela do módulo com dados das câmaras de fissão preenchido...........36

Figura 16: Tela do módulo com dados de outros materiais ...............................38

Figura 17: Tela do módulo com dados de outros materiais preenchido .................39

Figura 18: Comparação da queima de ${ }^{235} \mathrm{U}$, para o EC 193, nas várias configurações

Figura 19: Comparação da queima de ${ }^{235} U$, para o EC 194, nas várias configurações

Figura 20: Comparação da queima de ${ }^{235} U$, para o EC 195, nas várias configurações

Figura 21: Destaque da queima de ${ }^{235} \mathrm{U}$, para o EC 195, na configuração $218 \ldots . .49$ 


\section{CAPITULO 1 INTRODUÇÃO}

Toda instalação nuclear deve possuir um sistema de salvaguardas confiavel, cujo objetivo é o gerenciamento de material nuclear que permita avaliar a qualquer tempo, o inventário de cada um dos itens de material nuclear presentes numa instalação, além de indicar os locais onde estão estocados ou sendo utilizados. No reator de pesquisa IEA-R1, controla-se a queima de urânio e a produção de plutônio, sendo que na queima de urânio são registradas a massa total do elemento e de seu isótopo físsil $\left({ }^{235} \mathrm{U}\right)$, e na produção de plutônio, apenas a massa total do elemento é registrada.

Para os países signatários de acordos com a Agência Internacional de Energia Atômica (IAEA) [1], esse gerenciamento é essencial, pois, nas visitas regulares de inspetores deste órgão internacional, os dados relativos aos materiais nucleares, tais como, inventário de combustível queimado, inventário de urânio enriquecido, etc., devem estar disponíveis e calculados segundo procedimentos aceitos pela Comissão Nacional de Energia Nuclear (CNEN) e pela IAEA.

O desenvolvimento de sistemas de controle de material nuclear é um dos requisitos básicos para o licenciamento de uma instalação nuclear, conforme o item 7 da Norma CNEN - NE - 1.04 "Licenciamento de Instalações Nucleares", de Dezembro de 2002 [2].

A autorização para utilização de material nuclear só será concedida após a comprovação de que a instalação está pronta para receber o material nuclear e após o cumprimento, pelo requerente, das condições pertinentes exigidas na norma CNEN - NN - 2.02, "Controle de Materiais Nucleares", de Setembro de 1999.[3].

\subsection{HISTÓRICO}

O reator IEA-R1 é do tipo piscina aberta, refrigerado e moderado com água leve com refletores de berilio e grafite. 
O reator foi projetado e construído pela Babcock \& Wilcox Co., em um acordo com a Comissão Naconal de Energia Nuclear e financiado pelo governo dos Estados Unidos no programa "Átomos para a Paz".

NUELED DU REATUR IEA-Rt

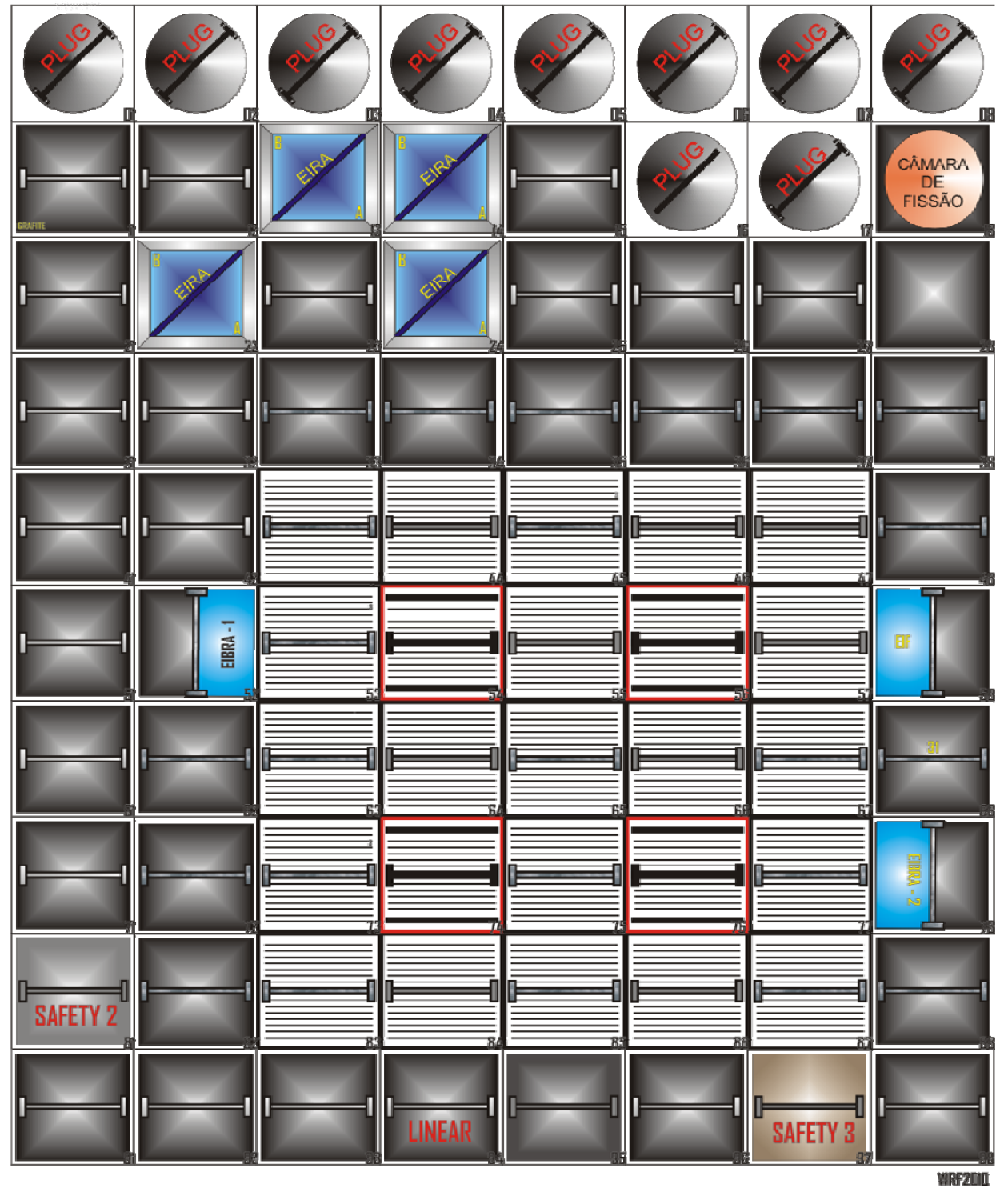

FIGURA 1 - Configuração basica do núcleo do reator

O núcleo do reator (Figura 1) é composto por 20 elementos combustíveis padrão (18 placas combustíveis), 4 elementos combustiveis de controle(12 placas combustíveis) e um elemento de irradiação de berilio colocado na posição central, organizados em uma matriz $5 \times 5$ e montados em uma placa matriz com 80 buracos. As posições da grade restantes são preenchidos com elementos refletorores e dispositivos experimentais (elementos de irradiação). 
Quatro monitores de nêutrons são posicionados acima do topo dos elementos refletores. A grade é suspensa por uma estrutura de alumínio afixada em uma ponte móvel localizado na parte superior da piscina.

O controle da queima dos elementos combustíveis usados nas diversas configurações do núcleo do reator IEA-R1 tem sido feito desde 1957, ano em que foi realizada a primeira operação deste reator.

Desta época até os dias de hoje, uma evolução nos recursos tecnológicos disponíveis para se realizar esta tarefa pode ser observada. Inicialmente, os cálculos eram realizados manualmente com a ajuda de calculadoras elétricas e eletrônicas. Posteriormente, com a possibilidade de uso de computadores, foi desenvolvido um programa utilizando a linguagem Fortran IV (1978) para efetuar esse cálculo. Neste caso, a alimentação de dados no computador de grande porte do IPEN era feita através de cartões perfurados e, após o processamento, um relatório impresso era gerado. Com o advento da micro-informática (1982), o programa original foi codificado para a linguagem Basic (MBR.BAS), sendo utilizado até os dias atuais, com algumas modificações.

\subsection{DEFINIÇÕES}

Apresentamos a seguir as definiçòes de alguns termos utilizados neste trabalho [3]:

Acordo de Salvaguardas - Acordo entre dois ou mais países, entre si, ou com uma ou mais Agências, que tem por objetivo a contabilidade e o controle de material nuclear, estabelecendo um compromisso desses países para o uso exclusivamente pacífico da energia nuclear.

Área de Balanço de Material - Área pertencente a uma instalação, ou outro lugar, na qual se pode determinar:

a) a quantidade de material nuclear que entra e que sai da área;

b) o inventário físico do material nuclear presente na área.

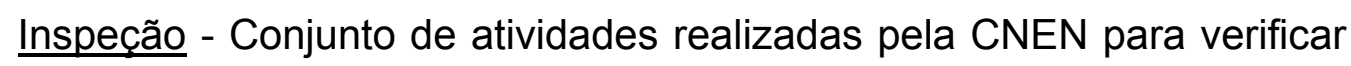
se o uso do material nuclear está conforme declarado. Estas atividades podem incluir outras verificações (outros materiais, instalações, equipamentos, serviços e 
informações). As atividades de inspeção incluem a verificação do questionário técnico, o exame de registros de contabilidade e de operação, a verificação da consistência entre registros e relatórios, a verificação do material nuclear, a verificação do funcionamento e da calibração de equipamentos de medida de material nuclear, aplicação e verificação dos dispositivos de contenção e equipamentos de vigilância e outras atividades necessárias para que a CNEN se assegure da conformidade de documentação, materiais e equipamentos com requisitos ou condições pré-determinadas ou aceitas pela CNEN

Instalação Nuclear - Instalação na qual o material nuclear é produzido, processado, reprocessado, utilizado, manuseado ou estocado em quantidades superiores a 1 (um) quilograma efetivo. Estão compreendidos nesta definição: reatores, plantas de conversão, plantas de fabricação, plantas de reprocessamento, plantas de separação de isótopos ou locais de armazenamento.

Material Nuclear - Urânio, Plutônio e Tório, sob qualquer forma, e, qualquer material que os contenha e, ainda, qualquer outro material que a CNEN venha a determinar no futuro. São excluídos desta definição minérios e ganga; 


\section{CAPITULO 2 OBJETIVO}

Este trabalho teve como objetivo o desenvolvimento de um programa computacional para gerenciamento do banco de dados de material nuclear de uma instalação. Para tanto, a linguagem de programação Visual Basic (Microsoft Corporation) foi sendo utilizada, uma vez que sua interface gráfica é amigável para o usuário.

A proposta do trabalho é que o programa desenvolvido tenha a capacidade de calcular a queima de urânio, a produção de plutonio, bem como, o inventário total de urânio e plutônio e atualizar arquivos contendo os registros referentes à salvaguarda de material nuclear e à gestão da qualidade do reator de pesquisa IEA-R1, pertencente ao Centro do Reator de Pesquisa (CRPq) do Instituto de Pesquisas Energéticas e Nucleares - IPEN-CNEN/SP. 


\section{CAPITULO 3 REVISÃO DA LITERATURA}

Pesquisadores de vários países desenvolvem trabalhos referentes ao gerenciamento de materiais nucleares e aos acordos internacionais de salvaguarda. A seguir são apresentados exemplos de trabalhos desenvolvidos nesta área.

Bencová, A. [4] apresenta como os materiais nucleares sob a jurisdição da República Eslovaca estão armazenados e como são utilizados em cinco instalações nucleares e em locais fora destas instalações (LOFs - Location Outside Facilities), materiais nucleares para finalidades não-nucleares. Estas atividades são executadas de acordo com regulamentos legais e compromissos internacionais de salvaguarda deste país.

Maceiras, E.; Fernández Moreno, S.; Castro, L.B.; Saavedra, A.D.; Mairal, M.L.; Valentino, L.I.; Vicens, H.E. y Llacer, C.D. [5] mostram em seu trabalho "Towards a new system of accounting of nuclear material" como a Autoridade Regulatória Nuclear (ARN) da Argentina garante o cumprimento das normas reguladoras nacionais no domínio nuclear e dos compromissos internacionais de salvaguardas assumidos por este país, especialmente aqueles relacionados à contabilidade e controle de materiais nucleares. Para cumprir esta responsabilidade, são realizadas inspeções e auditorias nacionais no operador de sistema contábil e de medição, gerando um grande volume de dados a serem processados e avaliados. Para gerir esta informação de forma eficiente, a ARN implementou um sistema de controle composto por três bases de dados: Sistema de Controle de Material Nuclear (SCMN), Sistema de Inspeção de Salvaguarda (SIS) e Sistema do Operador (SOP), que interagem entre si.

Sembiring, T.M. e Liem, P.H. [6], no trabalho "Development and verification of fuel burn-up calculation model in a reduced reactor geometry", afirmam que o nível de queima para cada elemento de combustível no núcleo é um dos parâmetros mais importantes para o gerenciamento de combustível nuclear.

Meftah, B., Halilou, A., Letaim, F., Mazidi, S., Mokedem, M.Y. e Zeggar, F. [7] apresentam o desenvolvimento do programa BURNUR.SYS para cálculo de 
"burn-up" baseado na linguagem DELPHI 7, que tem por finalidade, além do cálculo já referido, fornecer uma interface gráfica mais amigável aos usuários.

Friedman, G. H. [8], em seu relatório de auditoria "Nuclear Materials Accounting Systems Modernization Initiative", feito para o Departamento de Energia (DOE) do governo dos Estados Unidos da América, estima haver um gasto anual de cerca de 217 milhões de dólares para operar mais de 50 sistemas distintos de controle de material nuclear e executar outros procedimentos necessários para manter a prestação de contas sobre o inventário deste material. Devido ao fato destes sistemas não serem totalmente integrados, a obtenção de dados abrangentes sobre o material nuclear torna-se trabalhosa. Além dos muitos sistemas locais, O DOE também mantém o NMMSS (Nuclear Materials Management Safeguards System). Usado desde 1965, o NMMSS compreende um componente importante do sistema de contabilidade de material nuclear do Governo americano. Este sistema contém os dados sobre a quantidade, bem como dados de transações individuais em transferências de materiais nucleares, tanto internas como externas aos Estados Unidos da América. O Departamento de Energia e a Comissão Reguladora Nuclear (NRC) gastam na operação do NMMSS, 4 milhões de dólares anuais. Reconhecendo a ineficácia da manutenção de numerosos sistemas de monitoramento, o Departamento de Energia desenvolveu um estudo para modernizar os sistemas de gestão de materiais nucleares. 


\section{CAPITULO 4 MATERIAIS E MÉTODOS}

\subsection{VISUAL BASIC}

Todo programa deste trabalho foi desenvolvido utilizando a linguagem de programação VisualBasic (Microsoft Corporation), esta permite a criação de uma interface amigável entre o operador e o sistema. [13]

Uma das maiores vantagens da interface gráfica é que o usuário pode interagir com um conjunto padronizado de objetos, tais como janelas, botões e barras de deslocamento. Aplicativos que usam esses objetos padrões comportam-se de forma padrão, simplificando o aprendizado do aplicativo. Uma parte do trabalho do programador é selecionar o estilo de interação mais apropriado para a situação e escrever os seus programas de forma que possam ser utilizados intuitivamente pelo usuário.

Em um ambiente GUI (Graphical User Interface - Interface Gráfica com Usuário), o usuário interage com os objetos apresentados na tela, para dar início a eventos - abrir uma janela, dar um clique em um ícone, escolher um item de menu, e por meio disto, controlar o aplicativo. O Visual Basic transforma eventos iniciados pelo usuário em atividade programada, chamando o procedimento associado ao evento. A codificação que você insere no tal procedimento de evento implementa a resposta apropriada à interação com o objeto.

A Figura 2 apresenta a tela do ambiente de programação do VisualBasic, quando o sistema de programação é inicializado temos a janela "Form 1" onde devem ser colocados os ícones da coluna "General" localizada no lado esquerdo da tela. Cada ícone tem uma função especifica.

Na Figura 3 temos as linhas de programação referentes a cada ícone colocado no"Form".

A Figura 4 nos mostra a tela do "Form" preenchida, cada botão na parte inferior representa um módulo dentro do programa. 


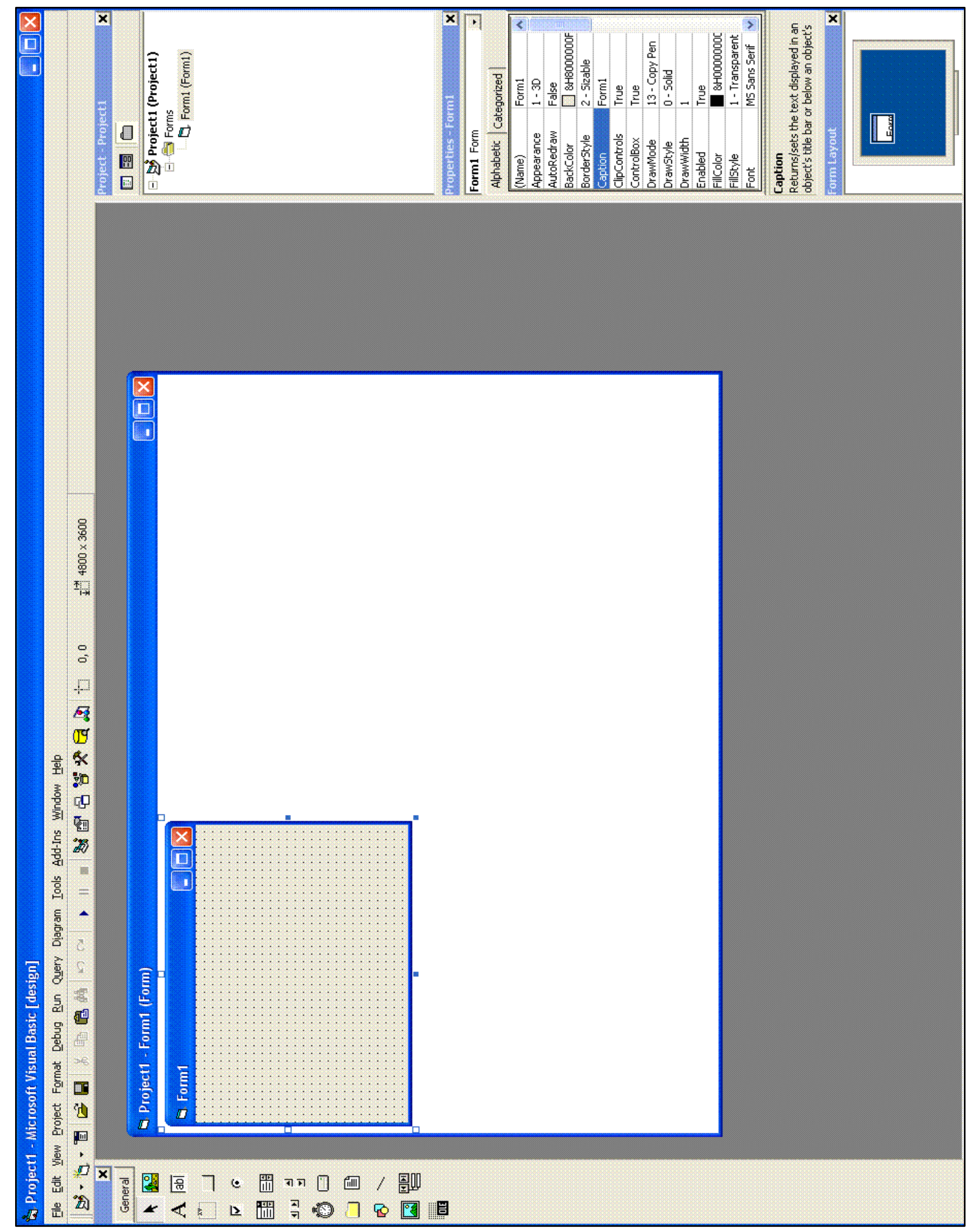

FIGURA 2 - Tela inicial do VisualBasic 


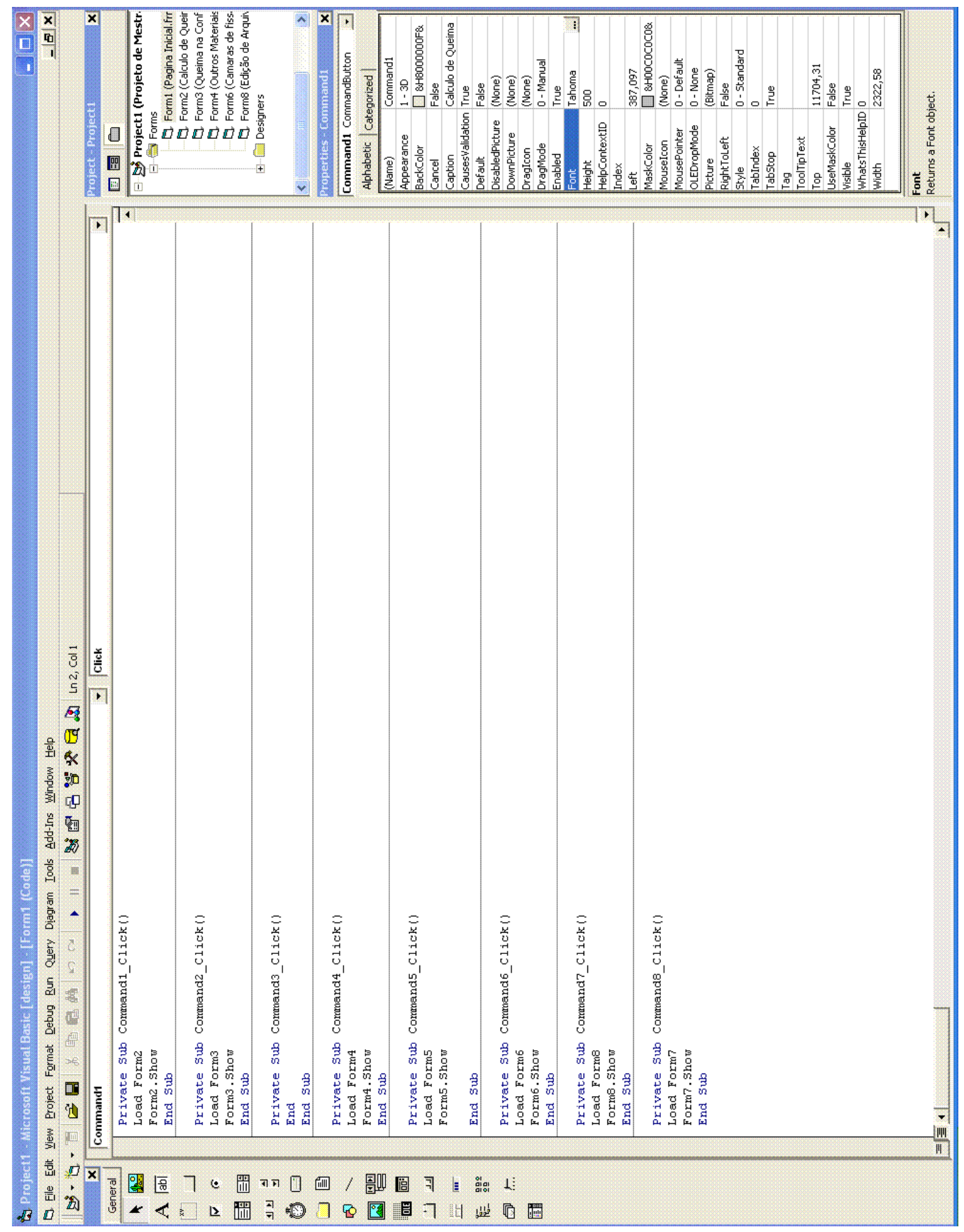

FIGURA 3 - Tela inicial do módulo de programação do VisualBasic 


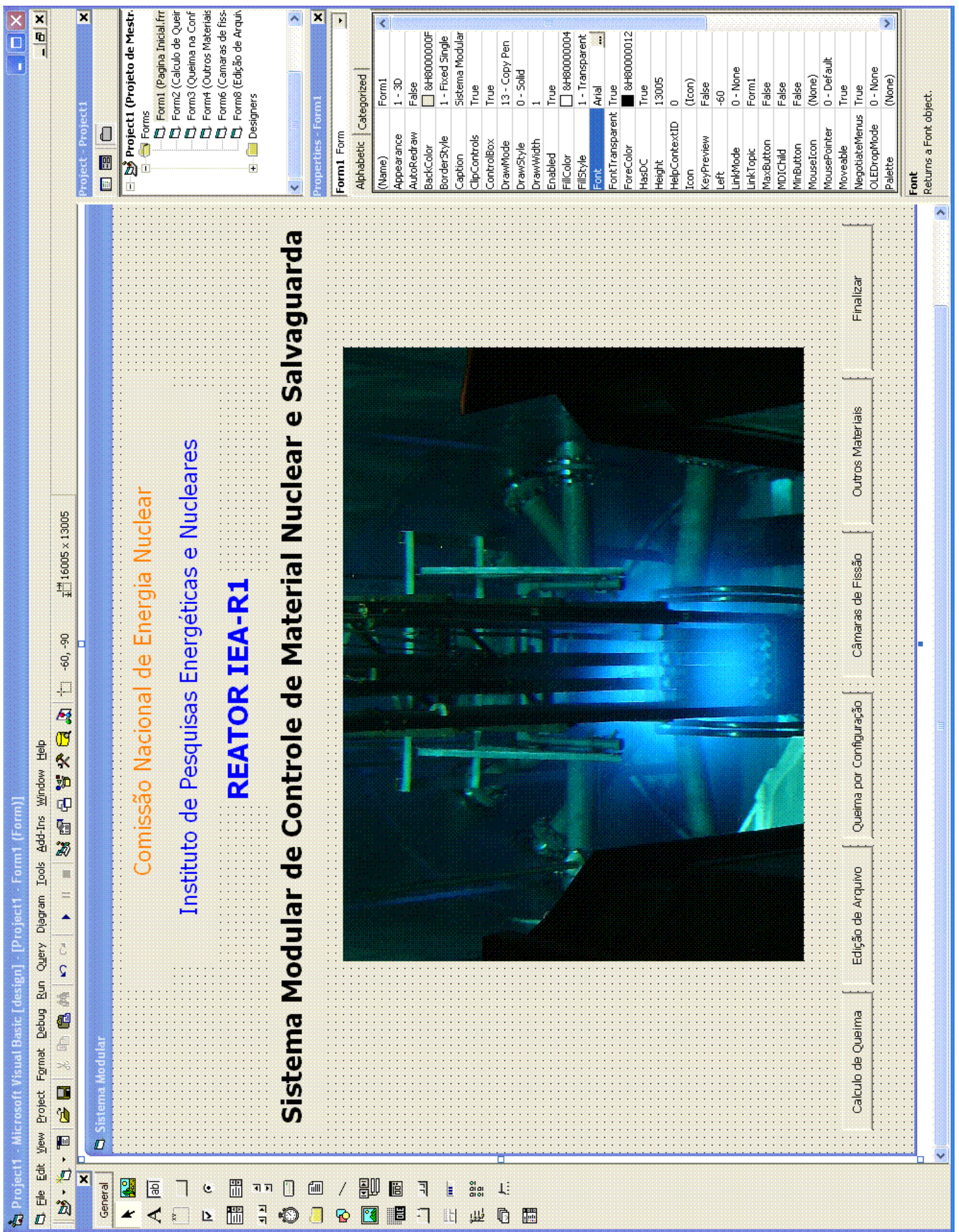

FIGURA 4 - Tela do módulo de programação do VisualBasic 


\subsection{MÉTODOLOGIA DE CÁLCULO}

Para o cálculo da queima de urânio e da produção de plutônio no reator IEA-R1 são considerados a energia dissipada durante a operação e o fluxo térmico médio na posição do elemento combustível no núcleo do reator.

\subsubsection{FATOR DE CONVERSÃO DA FISSÃO EM ENERGIA.}

Em geral, as unidades de energia são convertidas do nível microscópico (por exemplo, MeV) para unidades macroscópicas (por exemplo, $\mathrm{MWh}$ ). Isto vale no caso da energia nuclear, onde um número grande de fissões deve ocorrer para liberar uma quantidade macroscópica útil de energia. Supondo que uma fissão libera $200 \mathrm{MeV}$ de energia [9], então:

$$
1 \mathrm{~W}=1\left(\mathrm{~J} \mathrm{x} \mathrm{s}^{-1}\right) \times \frac{1}{1,602 \times 10^{-13}(\mathrm{~J} / \mathrm{MeV})} \times \frac{1}{200(\mathrm{MeV} / \text { fissão })}
$$

Onde: $\quad W=$ Watt

$\mathrm{J}=$ Joule

$\mathrm{s}=$ segundo

Mev $=1.602 \times 10^{-19} \mathrm{~J}$

$1 \mathrm{~W}=3,1 \times 10^{10}($ fissões $/ \mathrm{s})$

Dado que $A / N_{a}$ é a massa $(\mathrm{g})$ por átomo, a taxa em que o ${ }^{235} \mathrm{U}$ deve fissionar para gerar uma potencia de $1 \mathrm{MW}$ é dada por:

$$
1 \mathrm{MW}=3,1 \times 10^{16}(\text { fissões } / \mathrm{s}) \times 86400(\mathrm{~s} / \mathrm{d}) \times \frac{235}{6,023 \times 10^{23}}\left(\frac{\mathrm{g} \text { - fissionado }}{\text { atomo }- \text { fissionado }}\right)
$$

Onde:

$\mathrm{N}_{\mathrm{a}}=6,023 \times 10^{23} \mathrm{~mol}^{-1}$ (Constante de Avogadro)

$A=$ Numero de massa do elemento 
A fissão de $1 \mathrm{~g}$ de ${ }^{235} \mathrm{U}$ rende aproximadamente $1 \mathrm{MWd}$ de energia térmica. Entretanto, $85 \%$ dos nêutrons térmicos absorvidos pelo ${ }^{235} \mathrm{U}$ produzem fissão e os outros $15 \%$ das absorções produzem reações (n,y). Assim, a taxa do consumo de ${ }^{235} U$ é igual a taxa da fissão/0,85, ou seja,

$1 \mathrm{MWd}=1,24$ gramas de ${ }^{235} \mathrm{U}$ consumido.

Para cada dia de operação do reator, são registrados o tempo de operação e a energia dissipada $\left(E_{d}\right)$ em MWh. Utilizando estes dados é possível calcular a energia dissipada acumulada $\left(E_{\mathrm{da}}\right)$ no decorrer de cada mês. Ao término deste período, ou quando necessário, o valor da energia dissipada acumulada é usado para o cálculo da queima de ${ }^{235} \mathrm{U}$ correspondente.

\subsubsection{FLUXO DE NÊUTRONS TÉRMICOS MÉDIO NA POSIÇÃO.}

O acompanhamento da operação do reator de pesquisa IEA-R1 compreende cálculos dos parâmetros neutrônicos, tais como queima de combustível, distribuição de fluxos de nêutrons, densidade de potência e ganho de reatividade nas mudanças de configuração do núcleo, entre outros. Para o cálculo desses parâmetros, são utilizados os códigos de computação "LEOPARD", "TWODB" e "CITATION", que utilizam o modelo de célula (Fig 5). No programa computacional deste trabalho desenvolvido no $\mathrm{CRPq}$ do IPENCNEN/SP, para o cálculo de queima do combustível, são utilizados os valores do fluxo de nêutrons térmicos médio em cada posição do núcleo, os quais são obtidos a partir de um arquivo do programa "TWODB" [10].

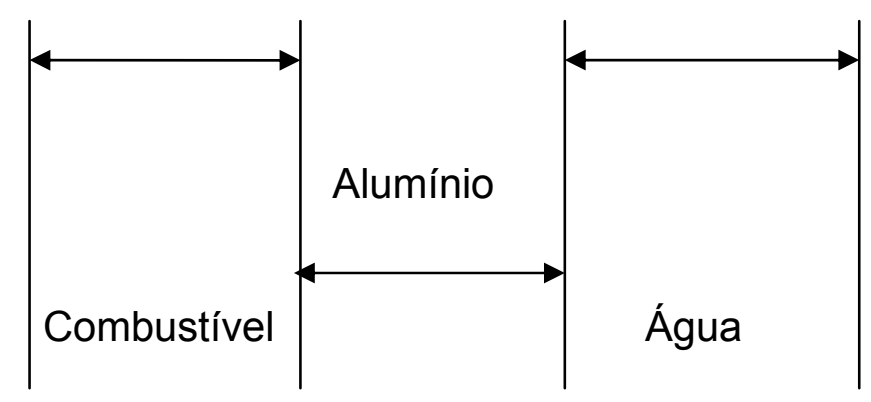

FIGURA 5- Esquema de uma célula básica utilizada no programa TWODB 


\subsubsection{CÁLCULO DE QUEIMA DE ${ }^{235} \mathrm{U}$.}

Conhecendo-se o valor do fluxo de neutrons térmicos em cada posição do núcleo pode-se calcular o fator $Q_{i} / Q_{m}$, ou seja, o quociente entre o fluxo térmico $Q_{i}$ e o fluxo médio $Q_{m}$.

Para cada posição do núcleo determina-se, ainda, um segundo fator que representa a relação existente entre a massa de ${ }^{235} U$ na posição i e a massa de ${ }^{235} \mathrm{U}$ total do núcleo.

A partir destes dois fatores, a queima de combustível é dada pela expressão:

$$
\mathrm{FQ}=\frac{\mathrm{M}_{\mathrm{i}}}{\mathrm{M}_{\mathrm{t}}} \times \frac{\mathrm{Q}_{\mathrm{i}}}{\mathrm{Q}_{\mathrm{m}}}
$$

Onde: $\quad M_{i}=$ Massa de ${ }^{235} U$ no elemento combustível;

$\mathrm{M}_{\mathrm{t}}=$ Massa total de ${ }^{235} \mathrm{U}$ no núcleo;

$Q_{i}=$ Fluxo térmico na posição;

$Q_{m}=$ Fluxo térmico médio no núcleo.

Normalizando-se $F Q$, obtem-se o fator de queima normalizado, de forma que:

$$
\sum_{\mathrm{i}=1}^{\mathrm{n}} \mathrm{FQN}=1
$$

onde $n$ é o número de elementos combustíveis.

A massa, em gramas, de ${ }^{235} \mathrm{U}$ queimado para a posição i ou para cada elemento combustível pode ser calculada a partir da expressão:

$$
Q T D Q=F Q N \times E_{d a} \times 1,24 / 24,
$$

onde 1,24 é o valor, em gramas, da massa de ${ }^{235} \mathrm{U}$ queimado para cada MWh de energia dissipada pelo reator. 


\subsubsection{CÁLCULO DA QUEIMA DE URÂNIO TOTAL}

Para o cálculo da queima de U-Total, é utilizada a seguinte expressão:

$$
\text { QTU = QTDQ } \times \text { 0,924 (para urânio 20\% enriquecido) [11] }
$$

\subsubsection{FORMAÇÃO DE PLUTÔNIO}

A formação de ${ }^{239} \mathrm{Pu}$ é expressa pela seguinte equação:

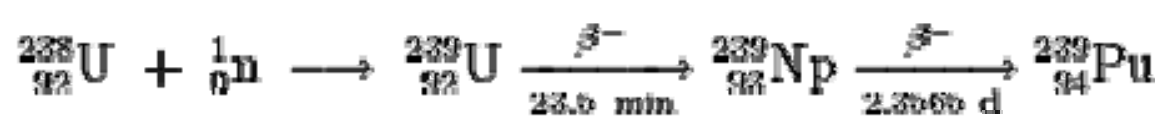

Para o cálculo da formação de ${ }^{239} \mathrm{Pu}$ é utilizada a seguinte expressão:

$P P=Q T D Q \times 0,096 / 1,24 \quad$ (para urânio 20\% enriquecido) [11]

Visto que os elementos combustíveis do reator IEA-R1 são eleborados com urânio enriquecido a $20 \%$ 


\section{CAPITULO 5 RESULTADOS}

Como resultado do trabalho desenvolvido são descritos os principais módulos e funções do programa computacional desenvolvido no CRPq do IPENCNEN/SP para gerenciamento do material nuclear do reator de pesquisa IEA-R1. Este programa é denominado "Sistema Modular de Controle de Material Nuclear e Salvaguarda". A cada tela apresentada é descrito o procedimento para obte-la e sua função.

\subsection{TELA PRINCIPAL}

A tela principal (Fig.6) do programa tem a finalidade de permitir, por meio de botões posicionados na sua parte inferior, o acesso a todos os módulos do sistema.

Os seis botões têm as seguintes funções:

Tabela 1 - Função dos Botões do Programa.

\begin{tabular}{ll}
\hline \multicolumn{1}{c}{ Botão } & \multicolumn{1}{c}{ Função } \\
\hline Cálculo de Queima & $\begin{array}{l}\text { Entra no módulo de cálculo da queima de urânio } \\
\text { e produção de plutônio }\end{array}$ \\
Edição de Arquivo & Entra no módulo de edição de arquivos \\
Queima por Configuração & $\begin{array}{l}\text { Entra no módulo de cálculo da queima de urânio } \\
\text { para uma determinada configuração }\end{array}$ \\
Camaras de Fissão & $\begin{array}{l}\text { Entra no módulo de gerenciamento do material } \\
\text { nuclear presente nas câmaras de fissão }\end{array}$ \\
Outros materiais & $\begin{array}{l}\text { Entra no módulo de gerenciamento do material } \\
\text { nuclear presente em outros itens da instalação }\end{array}$ \\
Finalizar & Encerra o programa \\
\hline
\end{tabular}




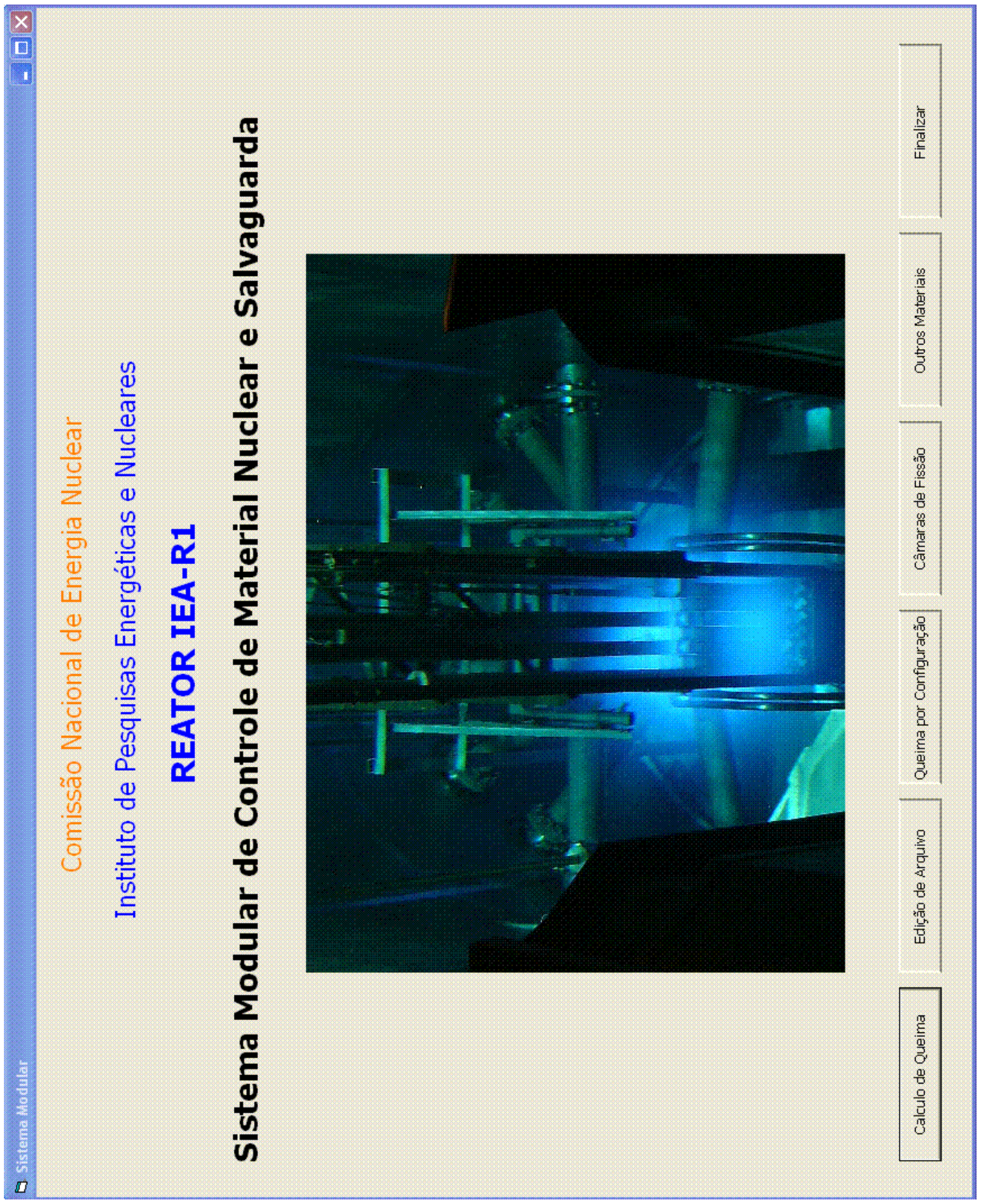

FIGURA 6- Tela principal apresentando os botões de funções do programa 


\subsection{MÓdULO PARA CÁlCULO DE QUEIMA DE ${ }^{235}$ U E PRODUÇÃo DE ${ }^{239} \mathrm{PU}$.}

Neste módulo (Fig. 7) são calculados a queima de ${ }^{235} \mathrm{U}$, U-Total e a produção de ${ }^{239} \mathrm{Pu}$ para cada elemento combustível que compõe uma determinada configuração do núcleo do reator IEA-R1.

Para a entrada de dados, as seguintes informações devem ser fornecidas:

- "Energia Dissipada" - Valor da enegia dissipada no período considerado;

- "Arquivo de Entrada de Dados" - Nome do arquivo de entrada dos dados dos elementos combustíveis;

- "Arquivo de Saída de Dados" - Nome do arquivo de saída de dados, o qual que será gravado com os novos dados gerados;

- "Data de Início" - Data de início do período que será considerado;

- "Data de Término" - Data de término do período que será considerado;

- "Configuração" - Número da configuração a ser considerada;

- "No do Relatório" - Número do relatorio a ser gerado.

Neste módulo tem-se, ainda, seis botões com as seguintes funções:

- "Calcular" - Calcula a queima de ${ }^{235} \mathrm{U}$ e urânio-total e a produção de plutônio; estes cálculos são apresentados na tela central (Fig. 08);

- "Imprimir" - Imprime o documento "RELATÓRIO DE QUEIMA INDIVIDUAL DE URÂNIO E PRODUÇÃO DE PLUTÔNIO DOS ELEMENTOS COMBUSTIVVEIS" (Fig. 09);

- "Página Inicial" - Retorna para a página inicial do sistema (Fig. 6);

- "Edição de Arquivos" - Faz a edição de um arquivo de dados, quando necessário (Fig. 10);

- "Queima por configuração" - Entra no módulo "Queima por Configuração" (Fig. 12);

- "Finalizar" - Encerra o programa. 


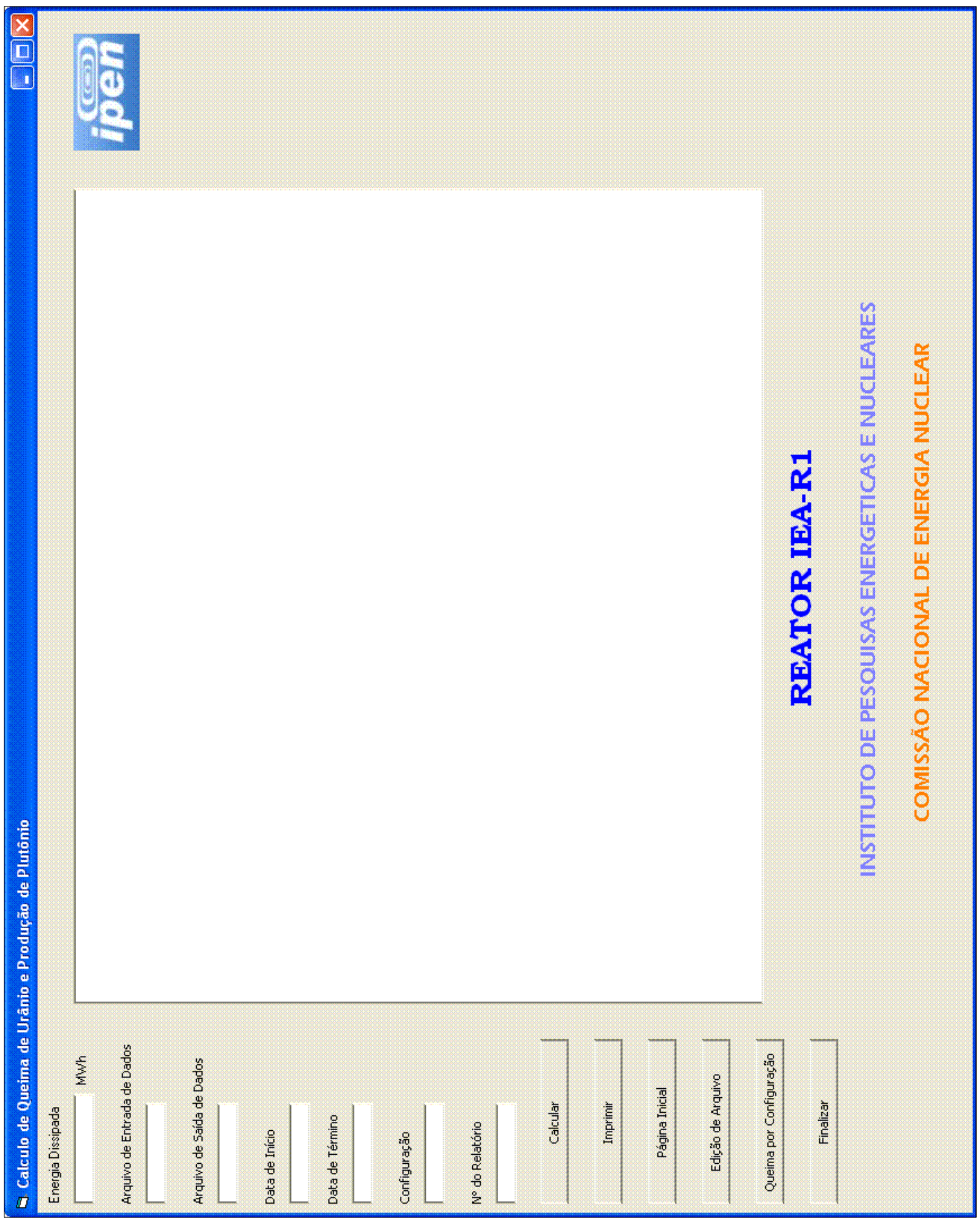

Figura 07- Tela do módulo para cálculo de queima de ${ }^{235} \mathrm{U}$ e Produção de ${ }^{239} \mathrm{Pu}$. 


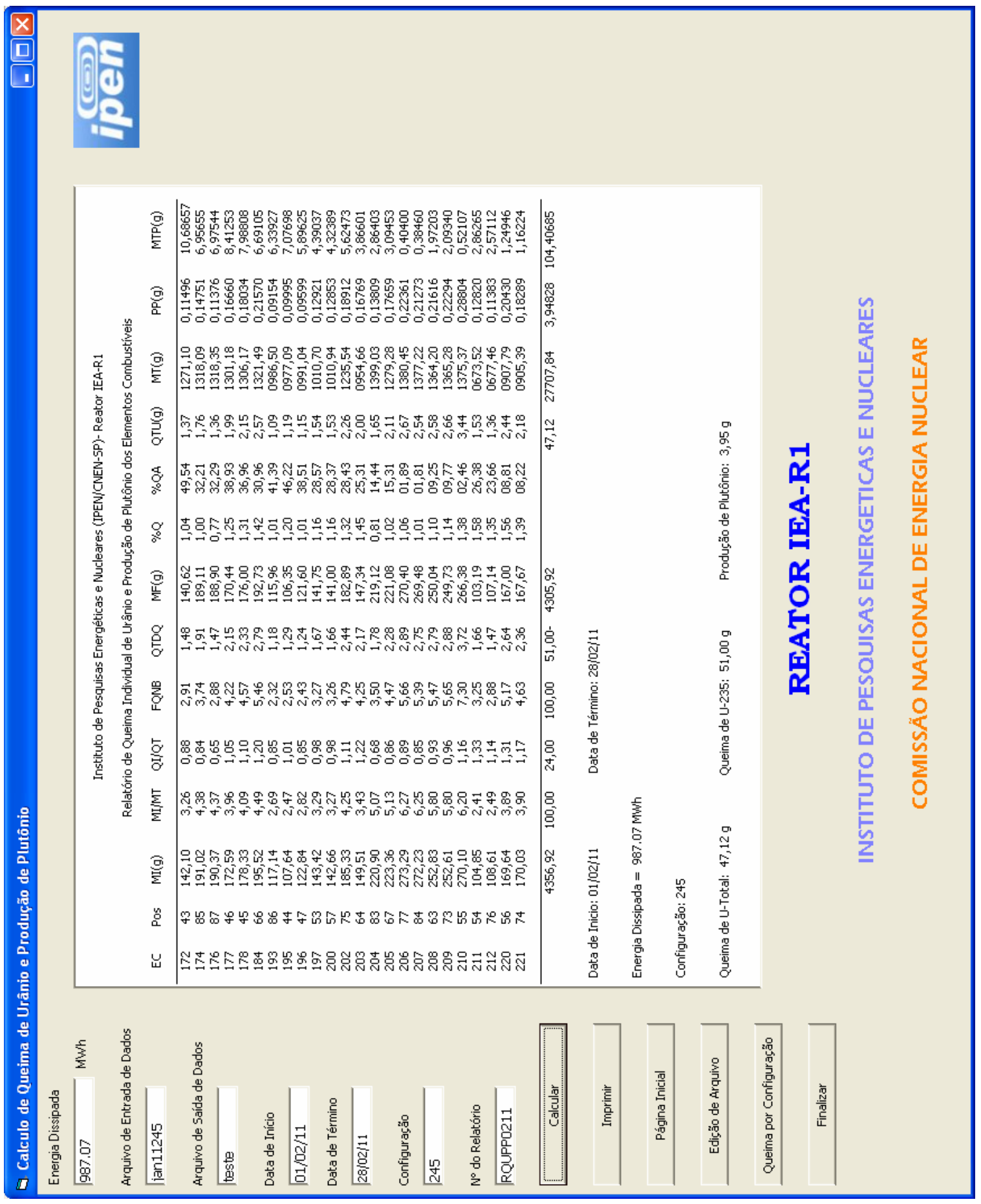

Figura 08 - Tela do módulo para cálculo de queima de ${ }^{235} \mathrm{U}$ e Produção de ${ }^{239} \mathrm{Pu}$ preenchido. 
Instituto de Pesquisas Energéticas e Nucleares (IPEN/CNEN-SP)- Reator IEA-R1

Relatório de Queima Individual de Urânio e Produção de Plutônio dos Elementos combustíveis

\begin{tabular}{|c|c|c|c|c|c|c|c|c|c|c|c|c|c|}
\hline EC & Pos & Mi(g) & $\mathrm{Mi} / \mathrm{Mt}$ & Oi/Oi & FONB & OTDO & Mf(g) & $\% 0$ & $\% \bigcirc A$ & OTU(g) & MT(g) & $P P(g)$ & MTP(g) \\
\hline 172 & 43 & 142,10 & 3,26 & 0,88 & 2,91 & 1,48 & 140,62 & 1,04 & 49,54 & 1,37 & 1271,10 & 0,11496 & 10,68657 \\
\hline 174 & 85 & 191,02 & 4,38 & 0,84 & 3,74 & 1,91 & 189,11 & 1,00 & 32,21 & 1,76 & 1318,09 & 0,14751 & 6,95655 \\
\hline 176 & 87 & 190,37 & 4,37 & 0,65 & 2,88 & 1,47 & 188,90 & 0,77 & 32,29 & 1,36 & 1318,35 & 0,11376 & 6,97544 \\
\hline 177 & 46 & 172,59 & 3,96 & 1,05 & 4,22 & 2,15 & 170,44 & 1,25 & 38,93 & 1,99 & 1301,18 & 0,16660 & 8,41253 \\
\hline 178 & 45 & 178,33 & 4,09 & 1,10 & 4,57 & 2,33 & 176,00 & 1,31 & 36,96 & 2,15 & 1306,17 & 0,18034 & 7,98808 \\
\hline 184 & 66 & 195,52 & 4,49 & 1,20 & 5,46 & 2,79 & 192,73 & 1,42 & 30,96 & 2,57 & 1321,49 & 0,21570 & 6,69105 \\
\hline 193 & 86 & 117,14 & 2,69 & 0,85 & 2,32 & 1,18 & 115,96 & 1,01 & 41,39 & 1,09 & 0986,50 & 0,09154 & 6,33927 \\
\hline 195 & 44 & 107,64 & 2,47 & 1,01 & 2,53 & 1,29 & 106,35 & 1,20 & 46,22 & 1,19 & 0977,09 & 0,09995 & 7,07698 \\
\hline 196 & 47 & 122,84 & 2,82 & 0,85 & 2,43 & 1,24 & 121,60 & 1,01 & 38,51 & 1,15 & 0991,04 & 0,09599 & 5,89625 \\
\hline 197 & 53 & 143,42 & 3,29 & 0,98 & 3,27 & 1,67 & 141,75 & 1,16 & 28,57 & 1,54 & 1010,70 & 0,12921 & 4,39037 \\
\hline 200 & 57 & 142,66 & 3,27 & 0,98 & 3,26 & 1,66 & 141,00 & 1,16 & 28,37 & 1,53 & 1010,94 & 0,12853 & 4,32389 \\
\hline 202 & 75 & 185,33 & 4,25 & 1,11 & 4,79 & 2,44 & 182,89 & 1,32 & 28,43 & 2,26 & 1235,54 & 0,18912 & 5,62473 \\
\hline 203 & 64 & 149,51 & 3,43 & 1,22 & 4,25 & 2,17 & 147,34 & 1,45 & 25,31 & 2,00 & 0954,66 & 0,16769 & 3,86601 \\
\hline 204 & 83 & 220,90 & 5,07 & 0,68 & 3,50 & 1,78 & 219,12 & 0,81 & 14,44 & 1,65 & 1399,03 & 0,13809 & 2,86403 \\
\hline 205 & 67 & 223,36 & 5,13 & 0,86 & 4,47 & 2,28 & 221,08 & 1,02 & 15,31 & 2,11 & 1279,28 & 0,17659 & 3,09453 \\
\hline 206 & 77 & 273,29 & 6,27 & 0,89 & 5,66 & 2,89 & 270,40 & 1,06 & 01,89 & 2,67 & 1380,45 & 0,22361 & 0,40400 \\
\hline 207 & 84 & 272,23 & 6,25 & 0,85 & 5,39 & 2,75 & 269,48 & 1,01 & 01,81 & 2,54 & 1377,22 & 0,21273 & 0,38460 \\
\hline 208 & 63 & 252,83 & 5,80 & 0,93 & 5,47 & 2,79 & 250,04 & 1,10 & 09,25 & 2,58 & 1364,20 & 0,21616 & 1,97203 \\
\hline 209 & 73 & 252,61 & 5,80 & 0,96 & 5,65 & 2,88 & 249,73 & 1,14 & 09,77 & 2,66 & 1365,28 & 0,22294 & 2,09340 \\
\hline 210 & 55 & 270,10 & 6,20 & 1,16 & 7,30 & 3,72 & 266,38 & 1,38 & 02,46 & 3,44 & 1375,37 & 0,28804 & 0,52107 \\
\hline 211 & 54 & 104,85 & 2,41 & 1,33 & 3,25 & 1,66 & 103,19 & 1,58 & 26,38 & 1,53 & 0673,52 & 0,12820 & 2,86265 \\
\hline 212 & 76 & 108,61 & 2,49 & 1,14 & 2,88 & 1,47 & 107,14 & 1,35 & 23,66 & 1,36 & 0677,46 & 0,11383 & 2,57112 \\
\hline 220 & 56 & 169,64 & 3,89 & 1,31 & 5,17 & 2,64 & 167,00 & 1,56 & 08,81 & 2,44 & 0907,79 & 0,20430 & 1,24946 \\
\hline \multirow[t]{2}{*}{221} & 74 & 170,03 & 3,90 & 1,17 & 4,63 & 2,36 & 167,67 & 1,39 & 08,22 & 2,18 & 0905,39 & 0,18289 & 1,16224 \\
\hline & & 4356,92 & 100,00 & 24,00 & 100,00 & 51,00 & 4305,92 & & & 47,12 & 27707,84 & 3,94828 & 104,40685 \\
\hline
\end{tabular}

Energia Dissipada $=987.07$ MWh Configuração: 245

Queima de U-Total: $47,12 \mathrm{~g} \quad$ Queima de U-235: $51,00 \mathrm{~g} \quad$ Produção de Plutônio: $3,95 \mathrm{~g}$

Responsảvel:

Relatório N: RQUPP0211

Figura 09 - Formulario gerado pelo módulo para cálculo de queima de ${ }^{235} \mathrm{U}$ e Produção de ${ }^{239} \mathrm{Pu}$. 


\subsection{EDITOR DE ARQUIVOS.}

Todos os arquivos utilizados neste programa são no formato ASCC II ou formato texto. Para facilitar a manipulação destes arquivos foi desenvolvido um editor de texto, que abre estes arquivos e permite a inserção ou retirada de dados (Fig. 10).

Esse editor de arquivos para Visual Basic foi desenvolvido utilizando instruções apresentadas por Manzano [12].

$\mathrm{Na}$ barra de comando superior temos o item "Arquivo", ao ser precionado são mostrados os itens "Abrir", para abrir o arquivo a ser editado e "Salvar" para gravar o arquivo que foi editado.

A Figura 11, apresenta um exemplo de arquivo editado.

Na parte inferior da tela temos dois botões com a seguintes funções:

- "Cálculo de Queima" - Tranfere o programa para o módulo "Cálculo de Queima de Uranio e Produção de Plutonio" (Fig.7).

- "Retornar Pagina Inicial" - Retorna a pagina inicial do sistema (Fig. 6). 


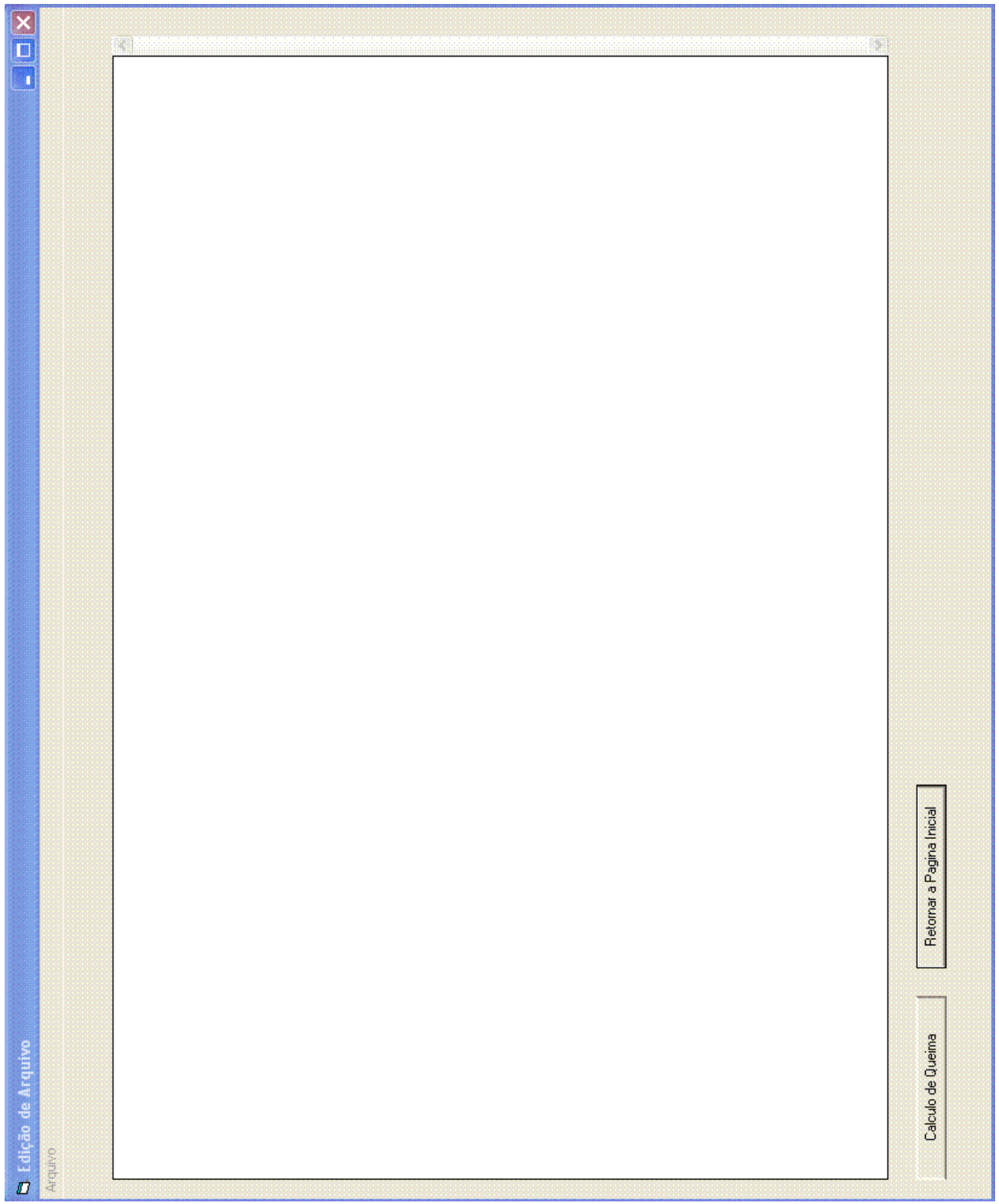

Figura 10 - Tela do módulo para edição de arquivo. 


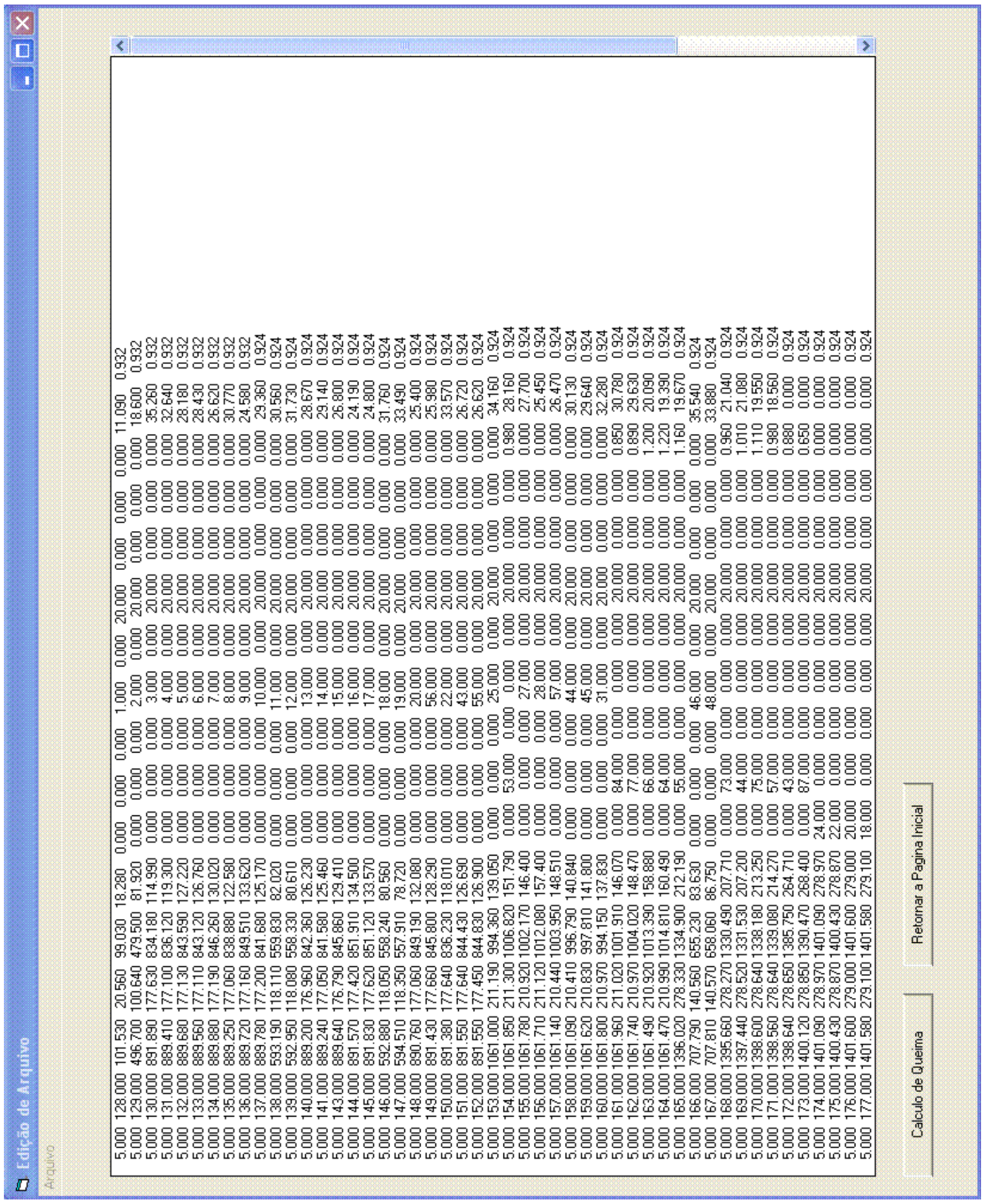

Figura 11 - Tela do módulo para edição de arquivo preenchido 


\subsection{QUEIMA POR CONFIGURAÇÃO}

Para todo elemento combustível recebido no Reator IEA-R1 é preenchido o formulário "REATOR IEA-R1: DADOS INDIVIDUAIS DOS ELEMENTOS COMBUSTIVEIS", este documento faz parte do sistemas de salvaguarda e qualidade, ele é necessario para iniciar um relato da trajetória do elemento combustível dentro da instalação. Esse formulario deve ser atualizado toda vez que o elemento muda de posição ou quando houver uma mudança de configuração do núcleo.

Este módulo do programa tem a finalidade de calcular a queima de cada elemento combustível em uma determinada configuração e gerar o formulario "Relatório Individual de Queima por Configuração" (Fig.07).

Este novo formulario, foi desenvolvido neste trabalho e após certificação passará a fazer parte dos documentos da Qualidade do Reator.

Para a entrada de dados temos cinco ïnputs", definidos a seguir:

- "Configuaração" - Número da configuração a ser calculada;

- "Arquivo de Dados Inicial" - Nome do arquivo do inicio da configuaração;

- "Arquivo de Dados Final" - Nome do arquivo do final da configuração;

- "Data de Início" - Data de início da configuração;;

- "Data de Término" - Data de término da configuração;;

Temos ainda quatro botões com as seguintes funções:

- "Calcular" - Calcula a queima de ${ }^{235} \mathrm{U}$ e urânio-total na configuração;

- "Imprimir" - Imprime o documento "Relatório Individual de Queima por Configuração";

- "Pagina Inicial" - Retorna a pagina inicial do sistema (Fig. 6);

- "Finalizar" - Encerra o programa. 


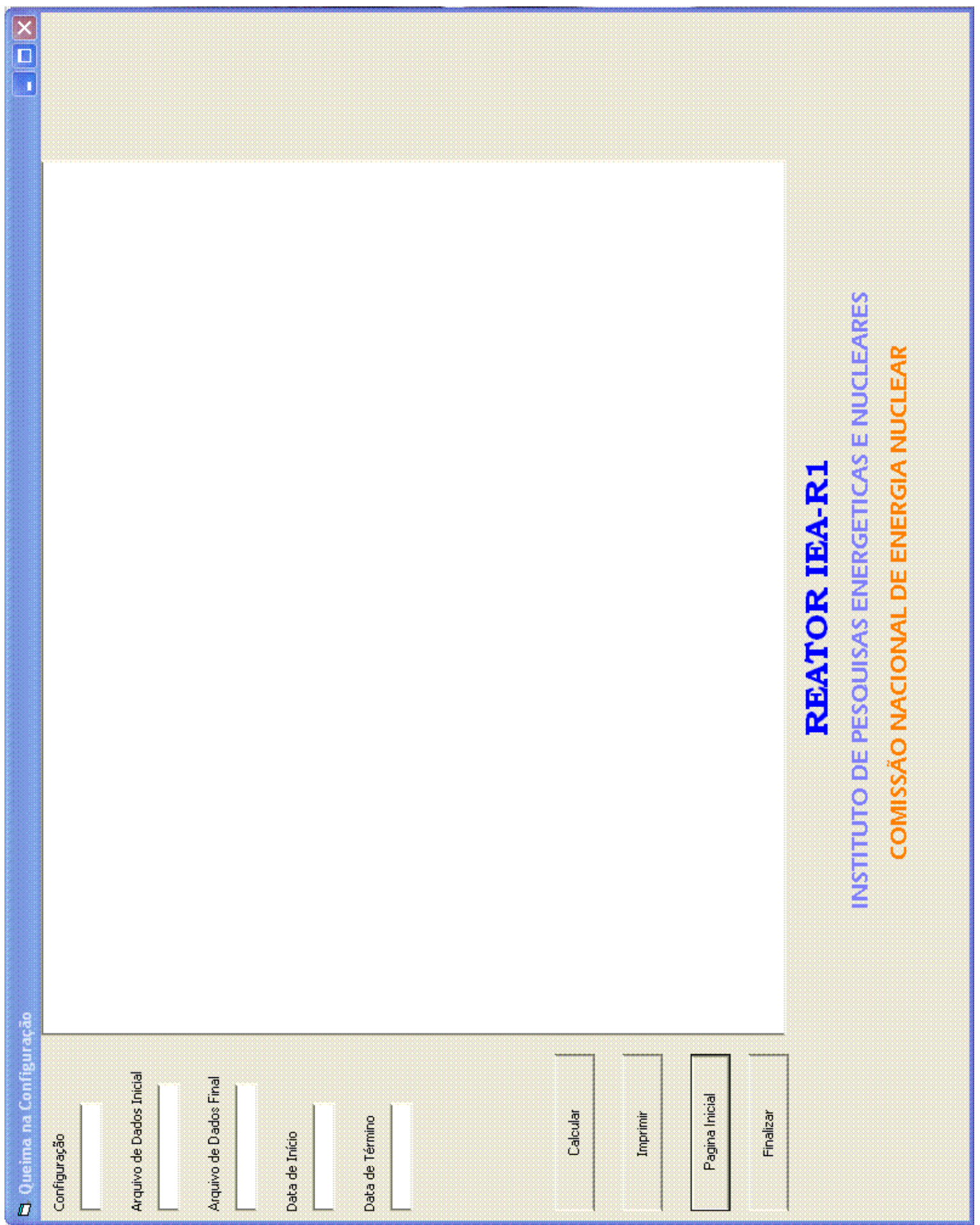

Figura 12 - Tela do módulo para cálculo de queima individual na configuração 


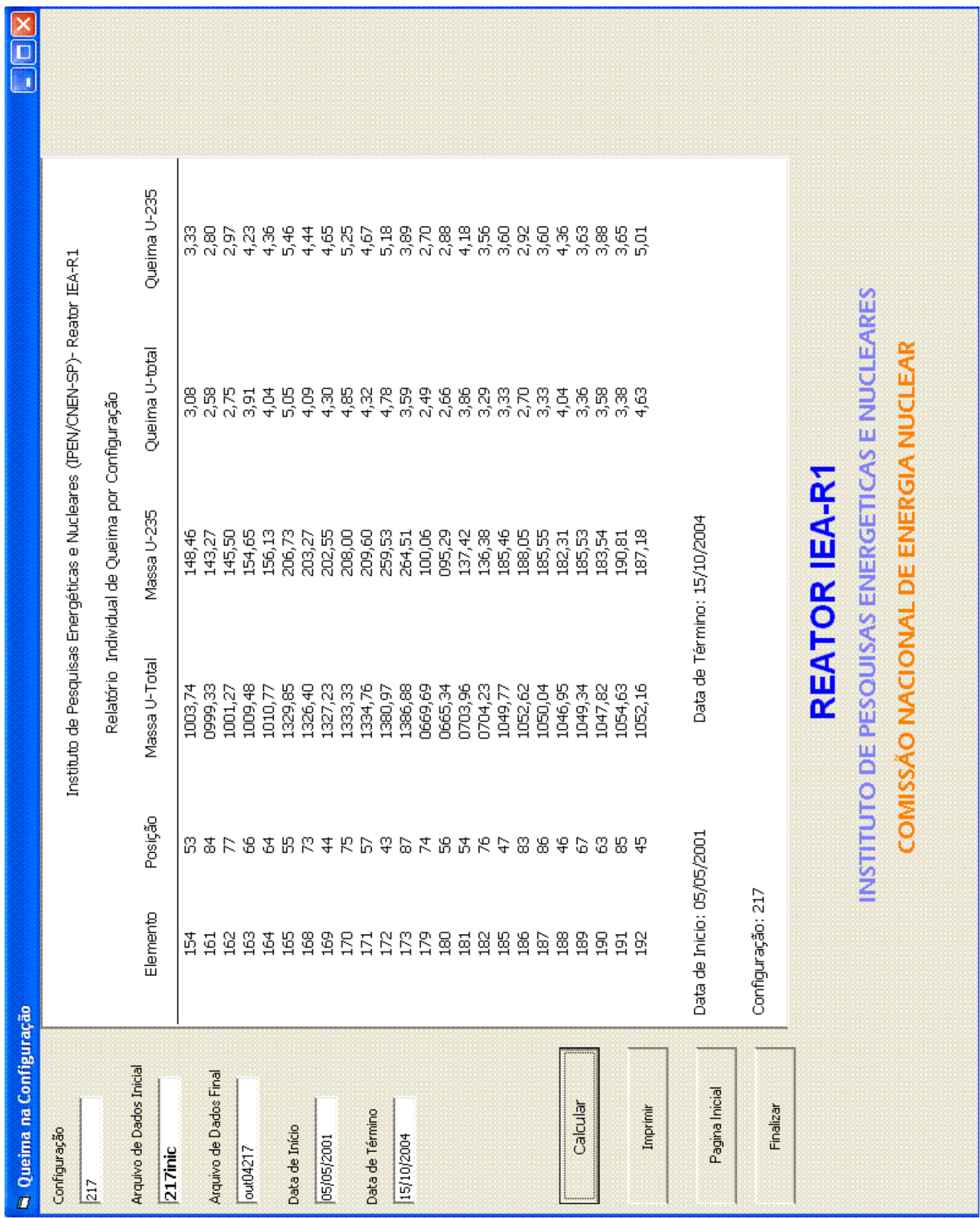

Figura 13 - Módulo para cálculo de queima individual na configuração preenchido. 


\subsection{CÂMARAS DE FISSÃO.}

As camaras de fissão utilizadas na operação do reator tem o seu material físsil contabilizado, para contabilidade desses itens foi desenvolvido um módulo especifico "Camaras de Fissão" (Fig.14) com dois "inputs" de dados e quatro botões operativos, como descritos a seguir:

- "Arquivo de Dados" - Nome do arquivo com dados das camaras de fissão;

- "Data" - Inserir data para emissão de relatorio impresso;

- "Configuração" - Numero da configuração do nucleo na data do relatório;

- "Abrir arquivo" - Abre o arquivo nominado acima;

- "Imprimir" - Imprime relatorio com os dados da janela central;

- "Pagina Inicial" - Retorna a pagina inicial do sistema (Fig. 6);

- "Finalizar" - Encerra o programa.

A Figura 15 mostra um exemplo desta tela preenchida 


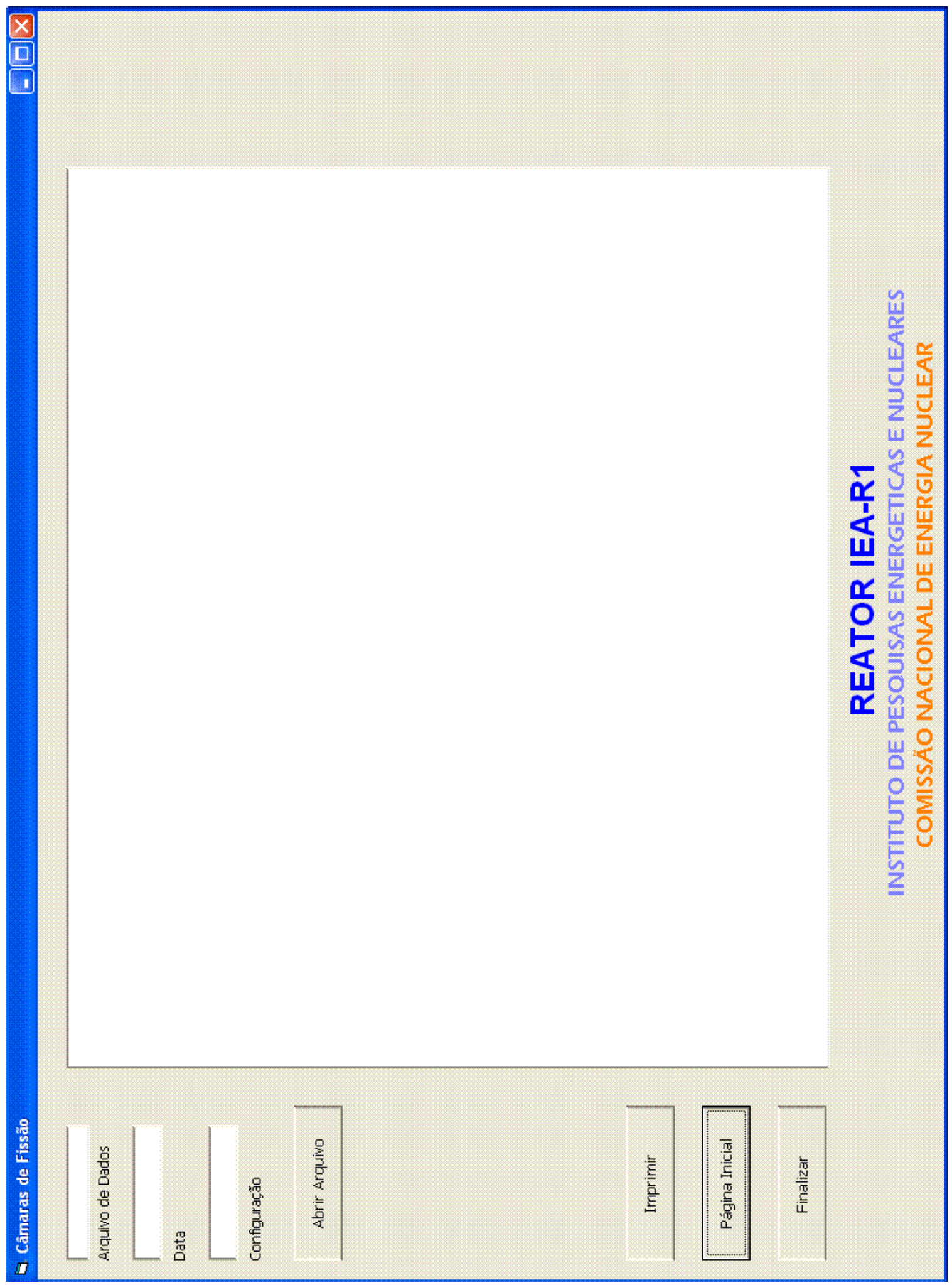

Figura 14 - Tela do módulo com dados das câmaras de fissão 


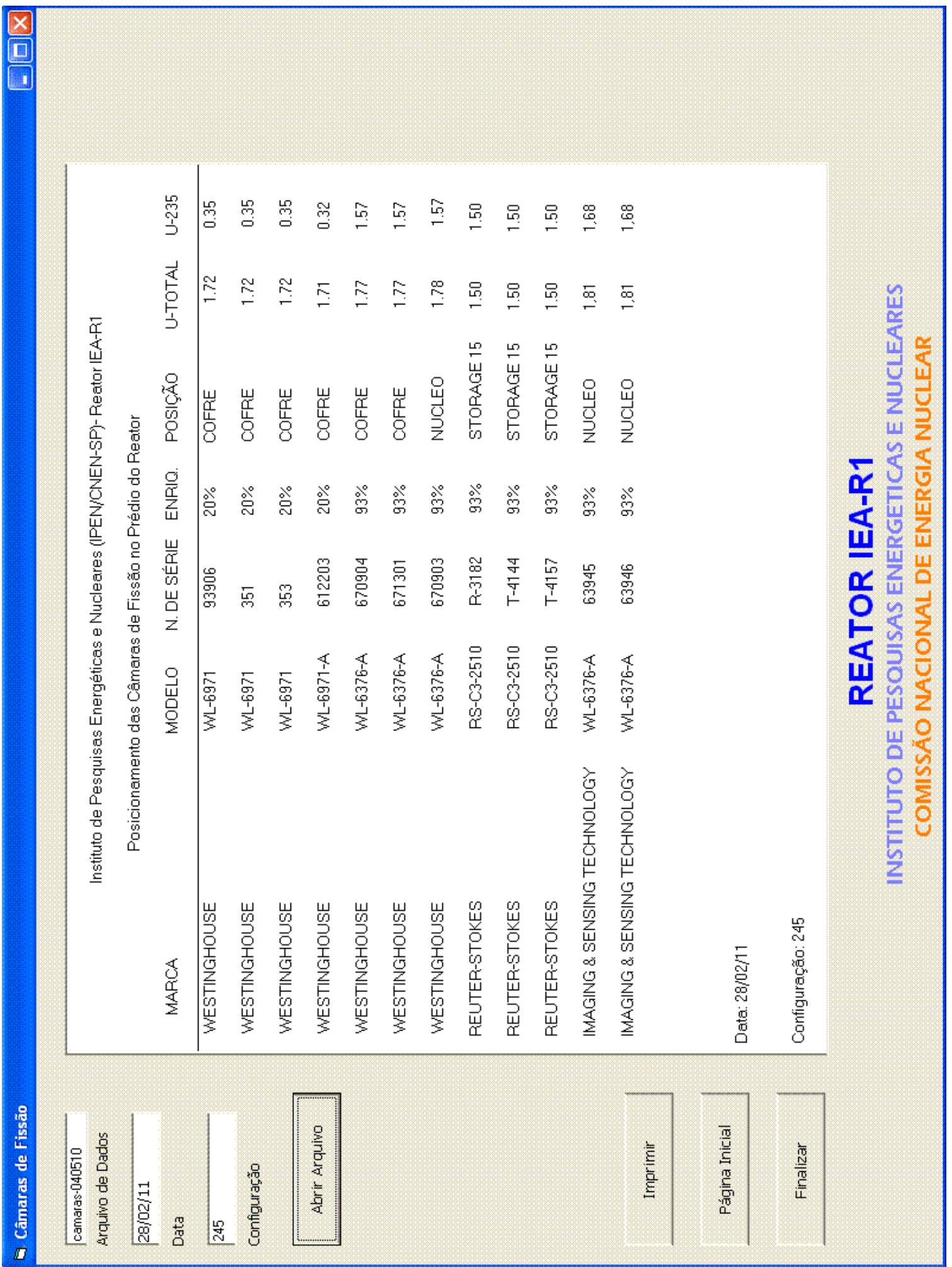

Figura 15 - Tela do módulo com dados das câmaras de fissão prenchido 


\subsection{OUTROS MATERIAIS.}

Eventualmente outros tipos de material nuclear salvaguardados podem ser encontrados dentro da instalação do Reator IEA-R1, a contabilidade desses itens foi incerido módulo especifico "Outros Materiais" (Fig.16) com dois "inputs" de dados e quatro botões operativos, como descritos a seguir:

- "Arquivo de Dados" - Nome do arquivo com dados sobre os materiais;

- "Data" - Inserir data para emissão de relatorio impresso;

- "Abrir arquivo" - Abre o arquivo nominado acima;

- "Imprimir" - Imprime relatorio com os dados da janela central;

- "Pagina Inicial" - Retorna a pagina inicial do sistema (Fig. 3);

- "Finalizar" - Encerra o programa.

A Figura 17 apresenta uma tela preenchida com os dados de materiais armazenados no reator IEA-R1 sob salvaguarda da Agencia Internacional de Energia Atômica (AIEA). 


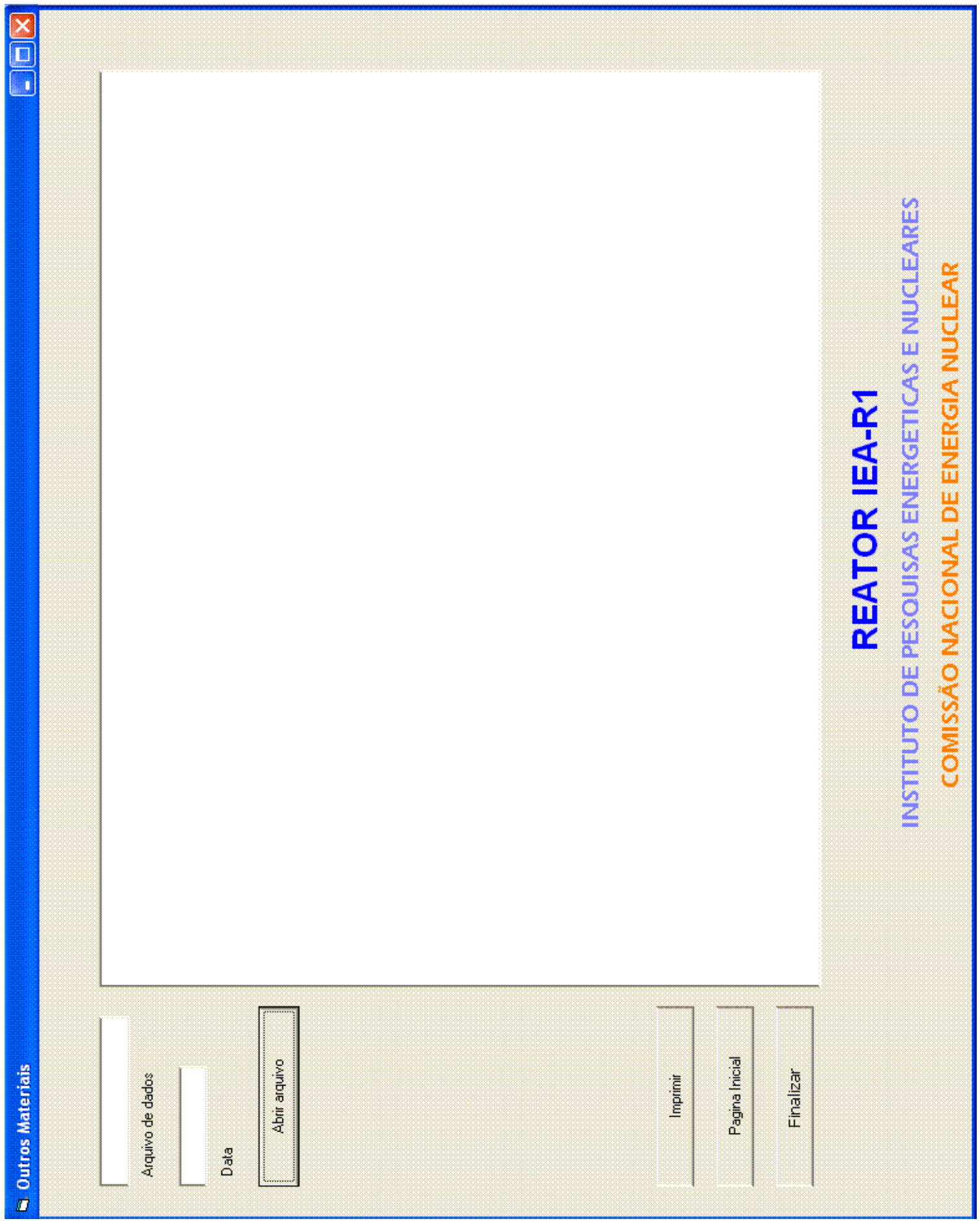

Figura 16 - Tela do módulo com dados de outros materiais 


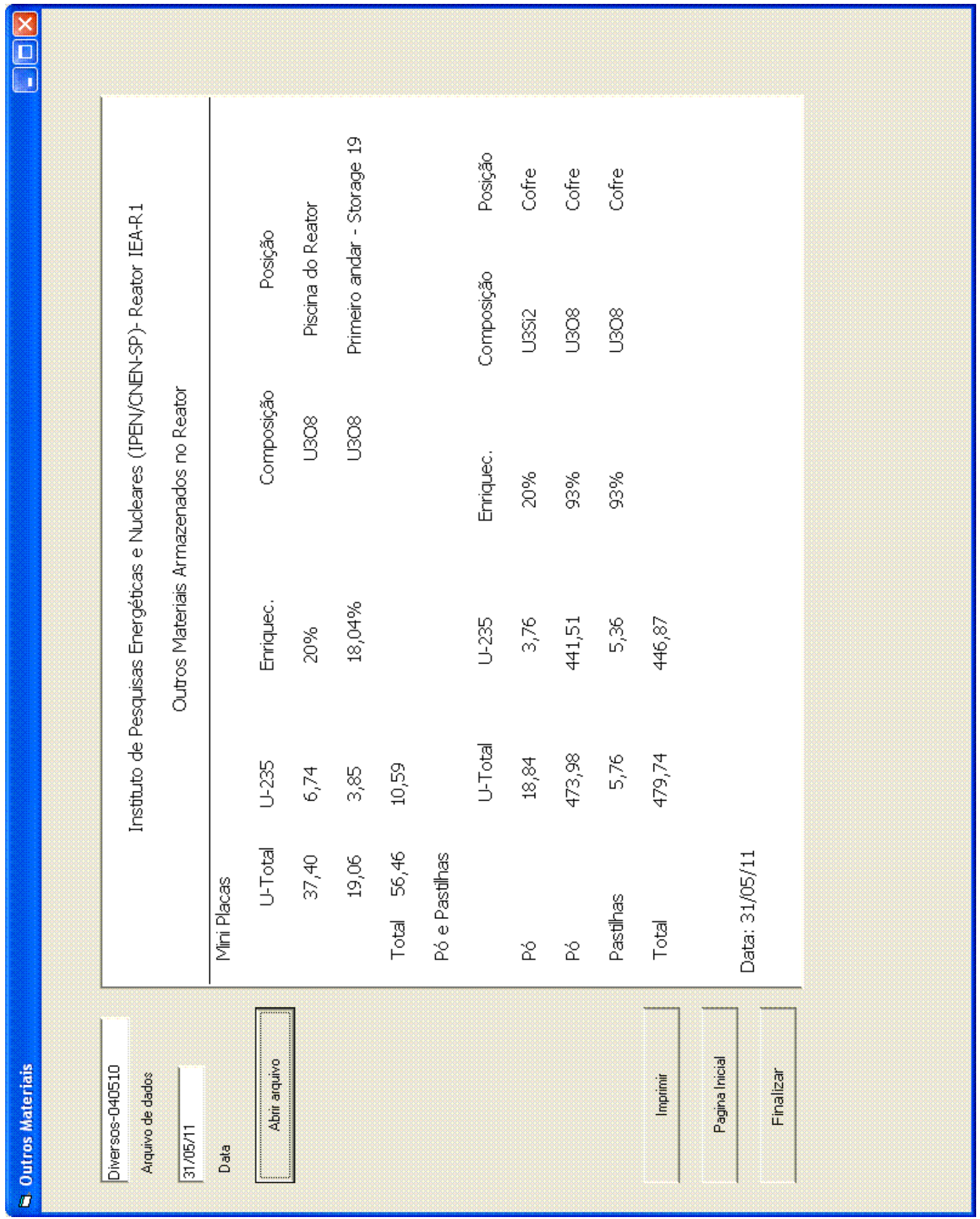

Figura 17 - Tela do módulo com dados de outros materiais preenchido 


\section{CAPITULO 6 ANALISE E DISCUSSÃO DE RESULTADOS}

Para que o Programa Computacional desenvolvido seja colocado em operação rotineira, substituindo o programa em uso atualmente, necessário se fez comprovar o seu desempenho no cálculo de queima de ${ }^{235} \mathrm{U}$. Para a comparação dos resultados obtidos pelos dois programas: a saber "programa atual" e programa novo" foram escolhidos os elementos combustíveis de número 193, 194 e 195 que entraram no núcleo do reator na configuração 218 no dia 03/11/04.

Estes elementos permaneceram no núcleo até o dia 13/12/2010 na configuração 244 no caso do elemento 194 e até o dia 30/05/2011 na configuração 245 no caso dos elementos 193 e 195.

Durante aproximadamente sete anos estes elementos permaneceram no núcleo do reator, nesse período foram calculadas as queima nas configurações 218, 219, 220, 221, 225, 226, 227, 228, 229, 230, 231, 232, 233, 234, 235, 236, 237, 237-A, 237-B, 238, 241, 242, 243, 243-A, 244 e 245.

Para cálculo das queimas nas respectivas configurações foram utilizados os módulos "MÓDULO PARA CÁLCULO DE QUEIMA DE ${ }^{235} U$ E PRODUÇÃO DE ${ }^{239}$ PU", "EDITOR DE ARQUIVOS" e "QUEIMA POR CONFIGURAÇÃO".

Para se ter uma base de confirmação dos resultados obtidos e analisar possíveis diferenças entre os dois programas de cálculo, utilizando as equações para cálculo de queima, foi desenvolvida uma planilha com o programa Excel (Microsoft Corporation), Anexo 1. Os resultados e comparações dos cálculos de queima de ${ }^{235} \mathrm{U}$ dos E.C. 193, 194 e 195 são apresentados nas tabelas de 2 à 6 .

Tabela 2 - Massa Final dos Elementos Combustiveis

\begin{tabular}{|c|c|c|c|}
\hline Numero do E.C. & $\begin{array}{c}\text { Massa Final (g) } \\
\mathbf{2 3 5} \mathbf{U} \text { (Excel) }\end{array}$ & $\begin{array}{c}\text { Massa Final (g) } \\
\mathbf{2 3 5} \mathbf{U} \text { (Novo) }\end{array}$ & $\begin{array}{c}\text { Massa Final (g) } \\
\mathbf{2 3 5}_{\mathbf{U}} \text { (Atual) }\end{array}$ \\
\hline 193 & 110,92 & 110,95 & 110,90 \\
\hline 194 & 115,08 & 115,11 & 115,16 \\
\hline 195 & 101,56 & 101,59 & 100,85 \\
\hline
\end{tabular}


Tabela 3 - Queima dos Elementos Combustiveis

\begin{tabular}{|c|c|c|c|}
\hline Numero do E.C. & $\begin{array}{c}\text { Queima } \\
\text { (Excel) }\end{array}$ & $\begin{array}{c}\text { Queima } \\
\text { (Novo) }\end{array}$ & $\begin{array}{c}{ }^{235} \mathbf{U}(\mathbf{g}) \\
\text { (Atual) }\end{array}$ \\
\hline 193 & 86,92 & 86,89 & 86,94 \\
\hline 194 & 83,19 & 83,16 & 83,11 \\
\hline 195 & 96,20 & 96,17 & 96,91 \\
\hline
\end{tabular}

Tabela 4 - Diferença de Queima dos Elementos Combustiveis com relação ao programa atual

\begin{tabular}{|c|c|c|c|c|}
\hline $\begin{array}{c}\text { Numero do } \\
\text { E.C. }\end{array}$ & $\begin{array}{c}\text { Diferença de } \\
\text { Queima (g) } \\
{ }^{235} \mathbf{U} \text { (Excel) }\end{array}$ & $\begin{array}{c}\text { Diferença de } \\
\text { Queima (g) } \\
{ }^{235} \mathbf{U} \text { (Novo) }\end{array}$ & $\begin{array}{c}\text { Erro (\%) } \\
\text { Excel }\end{array}$ & $\begin{array}{c}\text { Erro (\%) } \\
\text { Novo }\end{array}$ \\
\hline 193 & 0,02 & 0,05 & 0,023 & 0,058 \\
\hline 194 & 0,08 & 0,05 & 0,096 & 0,060 \\
\hline 195 & 0,71 & 0,74 & 0,733 & 0,764 \\
\hline
\end{tabular}

Tabela 5 - Cálculo da queima de ${ }^{235} \mathrm{U}$ na Configuração 218

\begin{tabular}{|c|c|c|c|}
\hline Programa Atual & Massa Inicial de ${ }^{235} \mathrm{U}(\mathrm{g})$ & Massa Final de ${ }^{235} \mathrm{U}(\mathrm{g})$ & $\begin{array}{c}\text { Queima de } \\
{ }^{235} \mathrm{U}(\mathrm{g})\end{array}$ \\
\hline 193 & 197,84 & 185,10 & 12,74 \\
\hline 194 & 198,27 & 184,93 & 13,34 \\
\hline 195 & 197,76 & 181,84 & 15,92 \\
\hline Programa Novo & & & \\
\hline 193 & 197,84 & 185,05 & 12,79 \\
\hline 194 & 198,27 & 184,86 & 13,41 \\
\hline 195 & 197,76 & 183,08 & 14,68 \\
\hline Planilha Excel & & & \\
\hline 193 & 197,84 & 185,05 & 12,79 \\
\hline 194 & 198,27 & 184,86 & 13,41 \\
\hline 195 & 197,76 & 183,07 & 14,69 \\
\hline
\end{tabular}


Tabela 6 - Cálculo da queima de ${ }^{235} \mathrm{U}$ na Configuração 219

\begin{tabular}{|c|c|c|c|c|}
\hline Programa Atual & $\begin{array}{c}\text { Massa Inicial } \\
\mathrm{de}{ }^{235} \mathrm{U}(\mathrm{g})\end{array}$ & $\begin{array}{c}\text { Massa Final } \\
\mathrm{de}{ }^{235} \mathrm{U}(\mathrm{g})\end{array}$ & $\begin{array}{c}\text { Queima de } \\
{ }^{235} \mathrm{U}(\mathrm{g})\end{array}$ & $\begin{array}{c}\text { iferença de } \\
\text { queima (g) } \\
\text { programa } \\
\text { atual e novo }\end{array}$ \\
\hline Programa Atual & & & & \\
\hline 193 & 185,10 & 173,86 & 11,24 & 0,03 \\
\hline 194 & 184,93 & 173,17 & 11,76 & 0,04 \\
\hline 195 & 181,84 & 169,17 & 12,67 & 0,16 \\
\hline Programa Novo & & & & \\
\hline 193 & 185,05 & 173,78 & 11,27 & \\
\hline 194 & 184,86 & 173,06 & 11,80 & \\
\hline 195 & 183,08 & 170,25 & 12,83 & \\
\hline Planilha Excel & & & & \\
\hline 193 & 185,05 & 173,77 & 11,28 & \\
\hline 194 & 184,86 & 173,06 & 11,80 & \\
\hline 195 & 183,08 & 170,25 & 12,83 & \\
\hline
\end{tabular}

Nas figuras 18,19, 20 são apresentados os resultados da queima de ${ }^{235} \mathrm{U}$ dos elementos combustíveis 193, 194 e 195 nas várias configurações que eles ocuparam durante sua vida útil. Os dados de referência das figuras 18, 19, 20 são apresentados nas tabelas 7,8 e 9 .

Na Figura 21 é apresentado em destaque a comparação da queima do elemento combustível 195 na configuração 218. 
Tabela 7 - Queima do Elemento Combustível 193

\begin{tabular}{|c|c|c|c|c|}
\hline $\begin{array}{c}\text { Número de } \\
\text { Configurações }\end{array}$ & $\begin{array}{c}\text { Configuração } \\
\text { do Núcleo }\end{array}$ & $\begin{array}{c}\text { Queima de } \\
{ }^{235} \mathrm{U}(\mathrm{g}) \\
\text { (Excel) }\end{array}$ & $\begin{array}{l}\text { Queima de } \\
{ }^{235} \mathrm{U}(\mathrm{g}) \\
\text { (Novo) }\end{array}$ & $\begin{array}{c}\text { Queima de } \\
{ }^{235} \mathrm{U}(\mathrm{g}) \\
\text { (Atual) }\end{array}$ \\
\hline 1 & 218 & 12,79 & 12,79 & 12,74 \\
\hline 2 & 219 & 11,28 & 11,27 & 11,24 \\
\hline 3 & 220 & 4,64 & 4,63 & 4,65 \\
\hline 4 & 221 & 5,51 & 5,51 & 5,54 \\
\hline 5 & 225 & 3,13 & 3,13 & 3,12 \\
\hline 6 & 226 & 3,08 & 3,08 & 3,08 \\
\hline 7 & 227 & 0,23 & 0,23 & 0,23 \\
\hline 8 & 228 & 0,09 & 0,09 & 0,09 \\
\hline 9 & 229 & 0,02 & 0,02 & 0,02 \\
\hline 10 & 230 & 0,05 & 0,05 & 0,05 \\
\hline 11 & 231 & 0,03 & 0,03 & 0,03 \\
\hline 12 & 232 & 0,04 & 0,04 & 0,04 \\
\hline 13 & 233 & 2,55 & 2,55 & 2,55 \\
\hline 14 & 234 & 0,61 & 0,61 & 0,61 \\
\hline 15 & 235 & 0,90 & 0,90 & 0,90 \\
\hline 16 & 236 & 4,02 & 4,02 & 4,03 \\
\hline 17 & 237 & 1,96 & 1,96 & 1,96 \\
\hline 18 & $237-A$ & 2,90 & 2,90 & 2,90 \\
\hline 19 & 237-B & 3,00 & 3,00 & 3,00 \\
\hline 20 & 238 & 7,26 & 7,26 & 7,26 \\
\hline 21 & 241 & 3,55 & 3,55 & 3,56 \\
\hline 22 & 242 & 3,14 & 3,14 & 3,15 \\
\hline 23 & 243 & 2,53 & 2,53 & 2,52 \\
\hline 24 & $243-A$ & 2,94 & 2,94 & 2,95 \\
\hline 25 & 244 & 5,03 & 5,02 & 5,02 \\
\hline 26 & 245 & 5,64 & 5,64 & 5,70 \\
\hline
\end{tabular}


Tabela 8 - Queima do Elemento Combustível 194

\begin{tabular}{|c|c|c|c|c|}
\hline $\begin{array}{c}\text { Número de } \\
\text { Configurações }\end{array}$ & $\begin{array}{l}\text { Configuração } \\
\text { do Núcleo }\end{array}$ & $\begin{array}{c}\text { Queima de } \\
{ }^{235} \mathrm{U}(\mathrm{g}) \\
\text { (Excel) }\end{array}$ & $\begin{array}{c}\text { Queima de } \\
{ }^{235} \mathrm{U}(\mathrm{g}) \\
\text { (Novo) }\end{array}$ & $\begin{array}{c}\text { Queima de } \\
{ }^{235} \mathrm{U}(\mathrm{g}) \\
\text { (Atual) }\end{array}$ \\
\hline 1 & 218 & 13,41 & 13,41 & 13,34 \\
\hline 2 & 219 & 11,80 & 11,80 & 11,76 \\
\hline 3 & 220 & 4,84 & 4,83 & 4,84 \\
\hline 4 & 221 & 5,74 & 5,73 & 5,74 \\
\hline 5 & 225 & 3,26 & 3,26 & 3,24 \\
\hline 6 & 226 & 2,94 & 2,93 & 2,94 \\
\hline 7 & 227 & 0,22 & 0,22 & 0,21 \\
\hline 8 & 228 & 0,09 & 0,09 & 0,09 \\
\hline 9 & 229 & 0,02 & 0,02 & 0,02 \\
\hline 10 & 230 & 0,04 & 0,04 & 0,04 \\
\hline 11 & 231 & 0,03 & 0,03 & 0,03 \\
\hline 12 & 232 & 0,04 & 0,04 & 0,04 \\
\hline 13 & 233 & 2,42 & 2,42 & 2,41 \\
\hline 14 & 234 & 0,58 & 0,58 & 0,58 \\
\hline 15 & 235 & 0,85 & 0,85 & 0,86 \\
\hline 16 & 236 & 3,82 & 3,82 & 3,84 \\
\hline 17 & 237 & 1,57 & 1,57 & 1,57 \\
\hline 18 & $237-A$ & 3,03 & 3,03 & 3,04 \\
\hline 19 & 237-B & 3,13 & 3,13 & 3,13 \\
\hline 20 & 238 & 7,57 & 7,57 & 7,56 \\
\hline 21 & 241 & 3,69 & 3,69 & 3,69 \\
\hline 22 & 242 & 3,26 & 3,26 & 3,27 \\
\hline 23 & 243 & 2,60 & 2,60 & 2,61 \\
\hline 24 & $243-A$ & 3,05 & 3,05 & 3,06 \\
\hline 25 & 244 & 5,19 & 5,19 & 5,20 \\
\hline
\end{tabular}


Tabela 9 - Queima do Elemento Combustível 195

\begin{tabular}{|c|c|c|c|c|}
\hline $\begin{array}{c}\text { Número de } \\
\text { Configurações }\end{array}$ & $\begin{array}{l}\text { Configuração } \\
\text { do Núcleo }\end{array}$ & $\begin{array}{c}\text { Queima de } \\
{ }^{235} \mathrm{U}(\mathrm{g}) \\
\text { (Excel) }\end{array}$ & $\begin{array}{c}\text { Queima de } \\
{ }^{235} \mathrm{U}(\mathrm{g}) \\
\text { (Novo) }\end{array}$ & $\begin{array}{c}\text { Queima de } \\
{ }^{235} \mathrm{U}(\mathrm{g}) \\
\text { (Atual) }\end{array}$ \\
\hline 1 & 218 & 14,69 & 14,68 & 15,92 \\
\hline 2 & 219 & 12,83 & 12,83 & 12,67 \\
\hline 3 & 220 & 5,23 & 5,23 & 5,20 \\
\hline 4 & 221 & 6,19 & 6,19 & 6,14 \\
\hline 5 & 225 & 3,50 & 3,50 & 3,46 \\
\hline 6 & 226 & 3,15 & 3,15 & 3,12 \\
\hline 7 & 227 & 0,23 & 0,23 & 0,23 \\
\hline 8 & 228 & 0,10 & 0,10 & 0,09 \\
\hline 9 & 229 & 0,02 & 0,02 & 0,02 \\
\hline 10 & 230 & 0,05 & 0,05 & 0,05 \\
\hline 11 & 231 & 0,03 & 0,03 & 0,03 \\
\hline 12 & 232 & 0,04 & 0,04 & 0,04 \\
\hline 13 & 233 & 2,60 & 2,60 & 2,58 \\
\hline 14 & 234 & 0,62 & 0,62 & 0,61 \\
\hline 15 & 235 & 0,91 & 0,91 & 0,91 \\
\hline 16 & 236 & 4,08 & 4,08 & 4,08 \\
\hline 17 & 237 & 1,67 & 1,67 & 1,66 \\
\hline 18 & 237-A & 3,32 & 3,32 & 3,30 \\
\hline 19 & 237-B & 3,42 & 3,42 & 3,40 \\
\hline 20 & 238 & 8,23 & 8,23 & 8,19 \\
\hline 21 & 241 & 3,99 & 3,99 & 3,97 \\
\hline 22 & 242 & 3,53 & 3,52 & 3,49 \\
\hline 23 & 243 & 2,79 & 2,79 & 2,79 \\
\hline 24 & $243-A$ & 3,26 & 3,26 & 3,25 \\
\hline 25 & 244 & 5,54 & 5,54 & 5,52 \\
\hline 26 & 245 & 6,18 & 6,17 & 6,19 \\
\hline
\end{tabular}




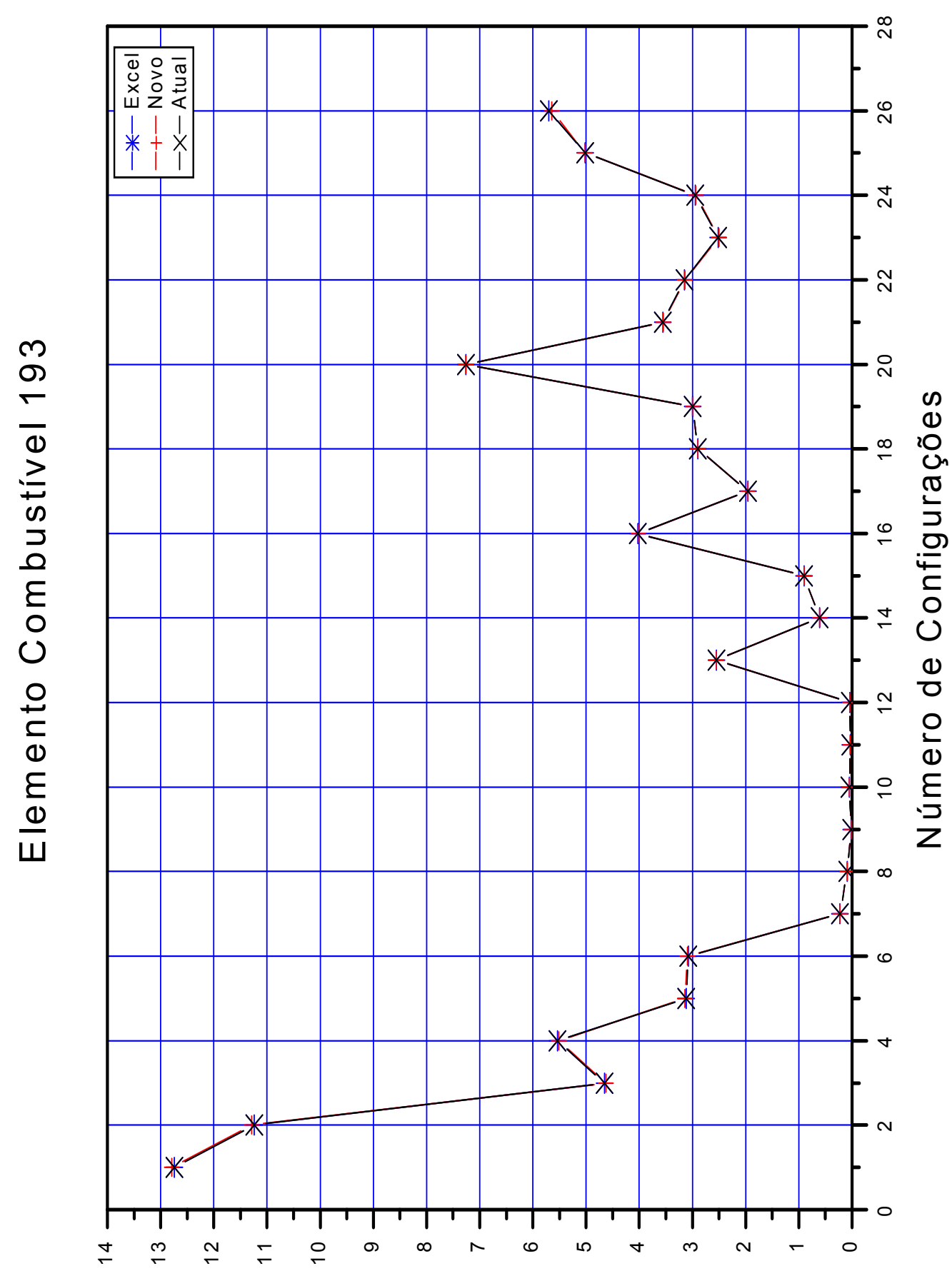

(6) oex̌eın6!̣uoว ıod em!əno

Figura 18 - Comparação da queima de ${ }^{235} \mathrm{U}$, para o EC 193, nas várias configurações. 


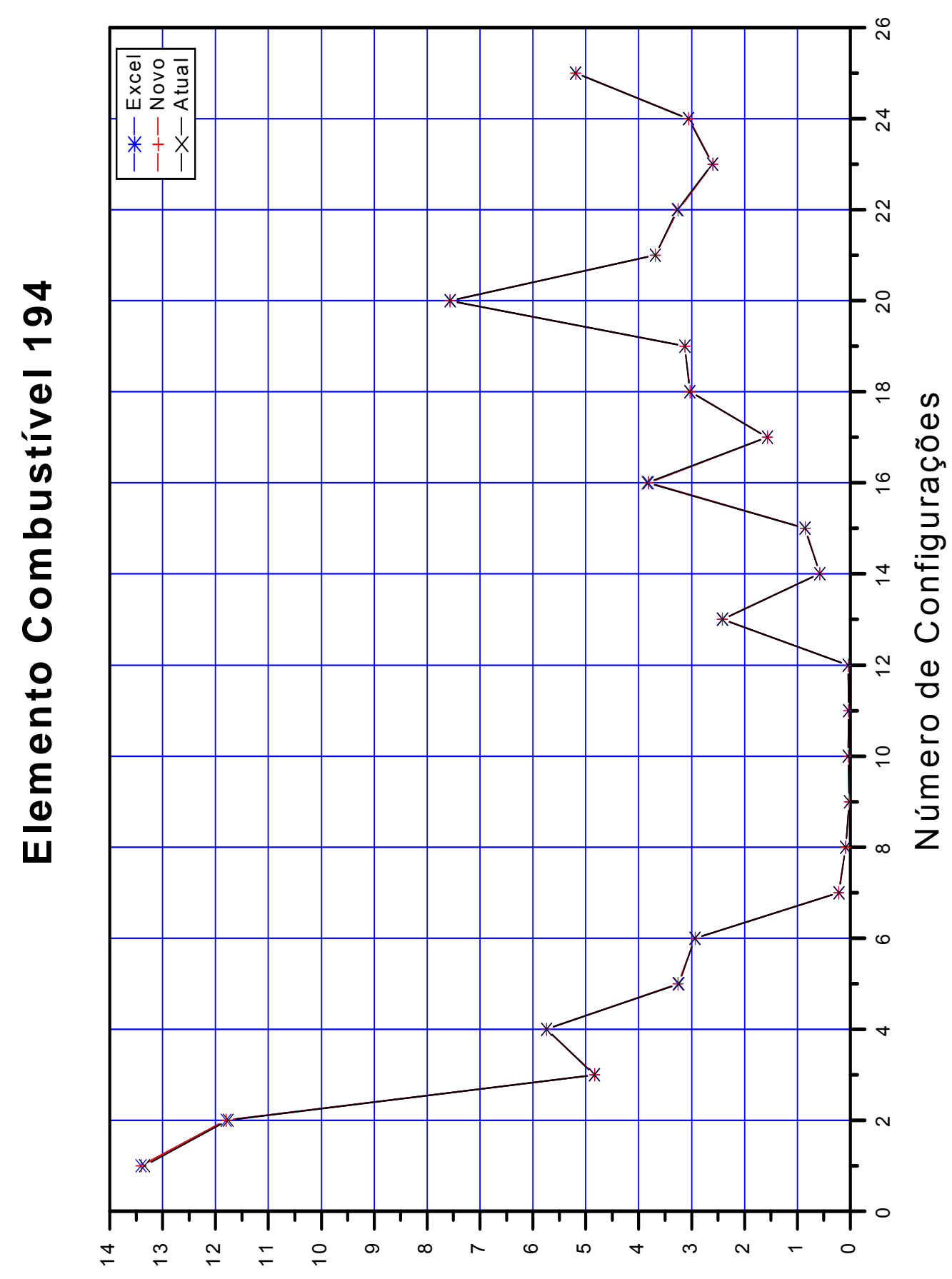

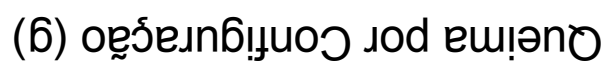

Figura 19 - Comparação da queima de ${ }^{235} \mathrm{U}$, para o EC 194, nas várias configurações. 


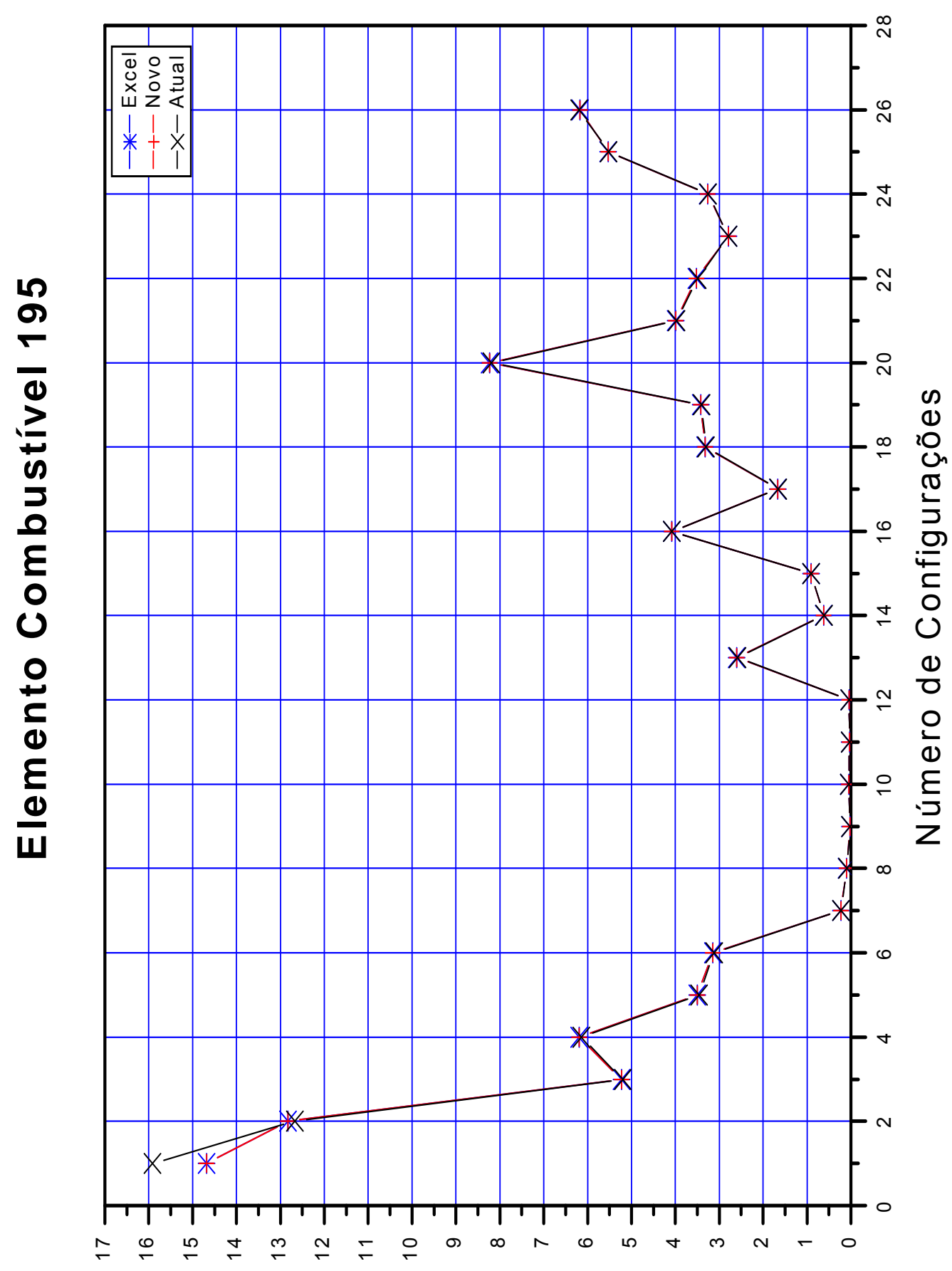

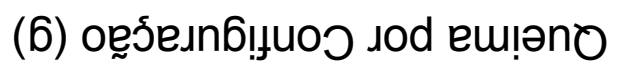

Figura 20 - Comparação da queima de ${ }^{235} \mathrm{U}$, para o EC 195, nas várias configurações. 


\section{Elemento Combustível 195}

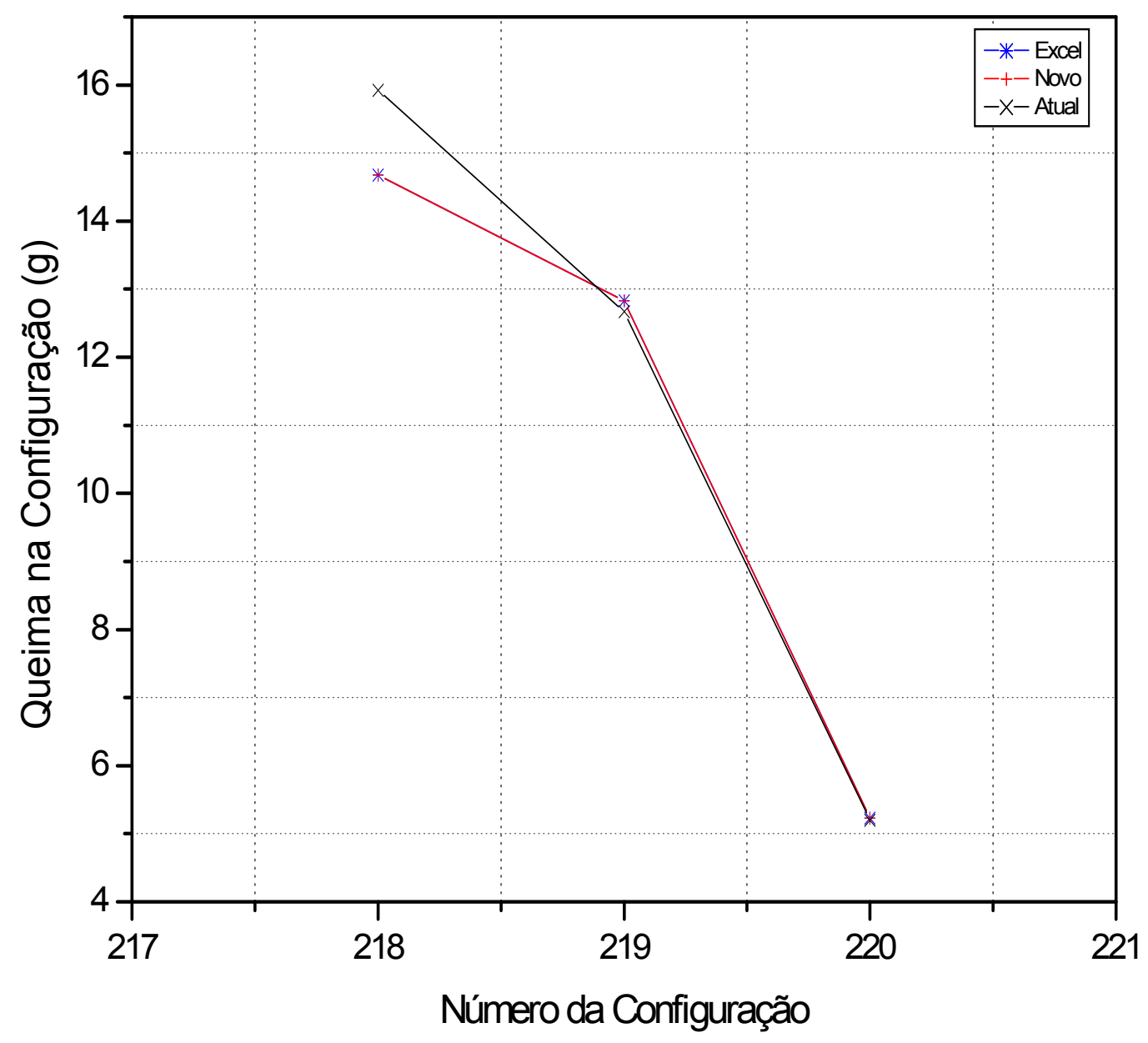

Figura 21 - Destaque da queima de ${ }^{235} \mathrm{U}$, para o EC 195, na configuração 218. 


\section{CONCLUSÃO}

O objetivo do trabalho foi alcançado uma vez que o programa computacional desenvolvido para aplicação no CRPq do IPEN-CNEN/SP para gerenciamento do material nuclear do reator de pesquisa IEA-R1 está concluído e operacional.

Dos resultados obtidos pode-se afirmar que não há diferenças consideráveis entre o novo programa (desenvolvido neste trabalho) e o que está em uso (programa atual). A maior diferença observada foi no cálculo da queima para o elemento 195 na configuração 218. Isto ocorre porque o procedimento de cálculo do programa atual soma os valores desprezados após a segunda casa decimal e adiciona-os ao valor da configuração 218. Mas, o resultado da queima total não apresenta essa variação.

O programa desenvolvido passa a ser utilizado para gerenciamento de banco de dados de material nuclear.

O relatório gerado pelo módulo "Cálculo de Queima de Urânio e Produção de Plutônio" é periodicamente enviado ao Serviço de Salvaguarda do IPEN-CNEN/SP, responsável pelo fornecimentos destes dados para a CNEN, que, por sua vez, os envia para a AIEA dentro dos acordos de salvaguarda.

O sistema de cálculo implementado neste programa contempla a necessidade dos pesquisadores que utilizam os valores de queima para comparálos com inspeções visuais [14].

Os elementos combustiveis fornecidos por fabricantes do exterior tinham garantia de queima de $30 \%$ de sua massa de ${ }^{235} \mathrm{U}$. Com o acompanhamento da queima facilitado pelo programa desenvolvido no CRPq, pode-se estabelecer, para os elementos combustíveis fabricados no IPENCNEN/SP, um nível de queima compatível com a sua integridade fisica [17].

Finalmente, o sistema de gerenciamento de material nuclear desenvolvido no reator de pesquisa IEA-R1 pode ser aplicado em reatores semelhantes, tendo em vista sua flexibilidade de utilização. 
TRABALHOS FUTUROS.

Algumas melhorias podem, no futuro, serem incorporadas ao sistema. Neste sentido, podem ser destacadas: possibilidade de leitura direta do fluxo térmico do arquivo gerado pelo programa TWODB; cálculo da porcentagem de queima; e condição de enriquecimento. 


\section{ANEXO - PLANILHA EXCEL}

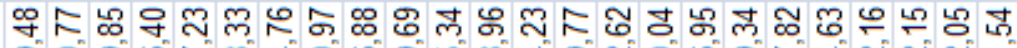
응으뉴ํำ

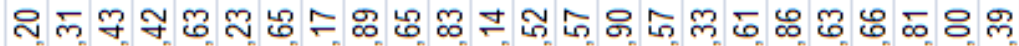

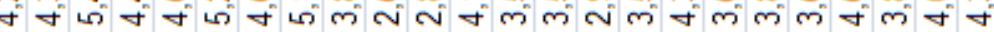

\section{돈}

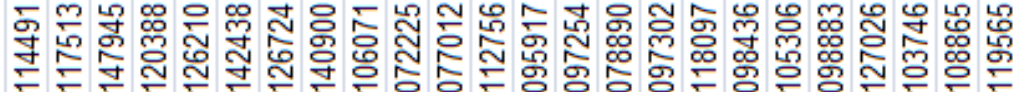

б́。்

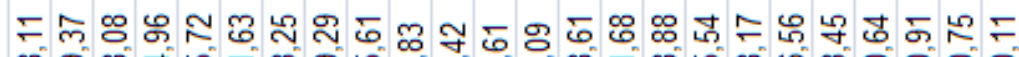

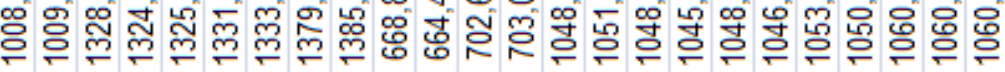

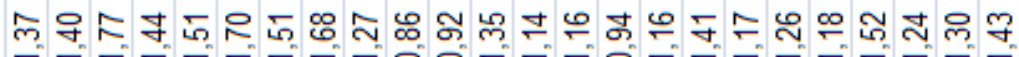

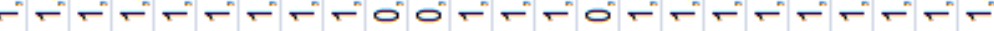

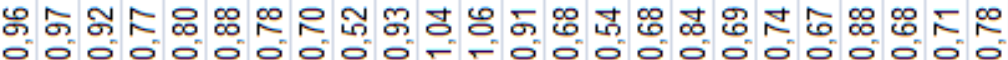

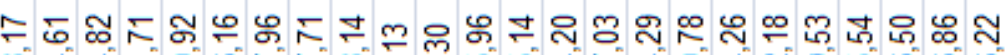

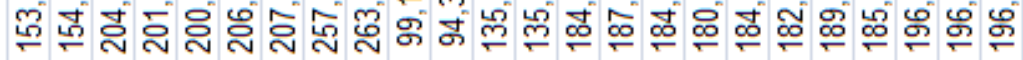

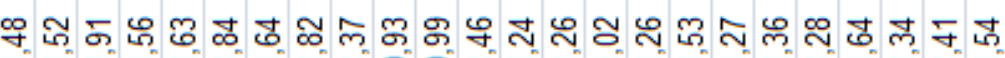

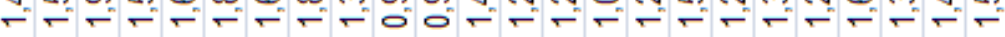

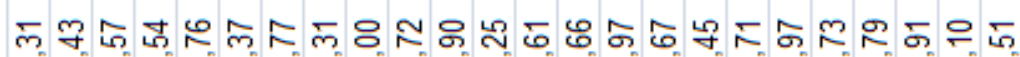

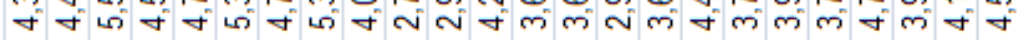

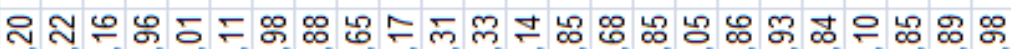

근드.

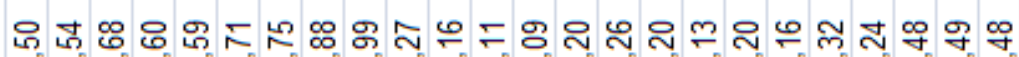

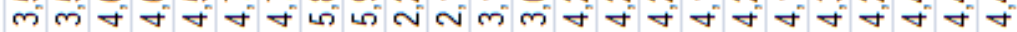

ํำ

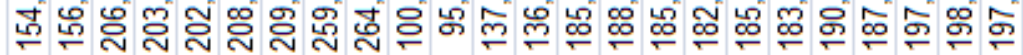

\section{ฮั}

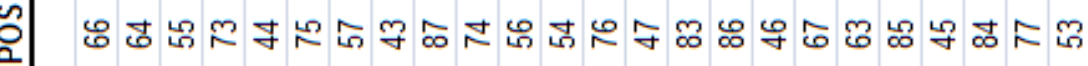

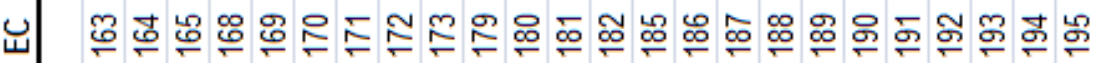




\section{REFERÊNCIAS BIBLIOGRÁFICAS}

1 IAEA Safeguards Glossary - 2001 - International Nuclear Verification Series $\mathrm{N}^{\circ} 3$

2 Norma CNEN - NE - 1.04 (Dezembro/2002) - Licenciamento de Instalações Nucleares

3 Norma CNEN - NN - 2.02 (Setembro/1999) - Controle de Materiais Nucleares

4 Bencová, A State System of Accounting for and Control of Nuclear Materials and Protocol Additional in the Slovak Republic - IAEA-SM$367 / 12 / 13$

5 Maceiras, E.; Fernández Moreno, S.; Castro, L.B.; Saavedra, A.D.; Mairal, M.L.; Valentino, L.I.; Vicens, H.E. y Llacer, C.D - 1998 - Towards a New System of Accounting of Nuclear Material - 39th Annual Meeting of the Institute of Nuclear Material Management (INMM).Naples, EUA

6 Sembiring, Tagor Malem e Liem, Peng Hong, Development and verification of fuel burn-up calculation model in a reduced reactor geometry - Annals of Nuclear Energy 35 (2008) 167-174

7 B. Meftah, A. Halilou, F. Letaim, S. Mazidi, M.Y. Mokeddem, F. Zeggar BURNUR.SYS: A 2-D code system for NUR research reactor burn up analysis - Annals of Nuclear Energy 35 (2008) 591-600

8 Friedman G. H. - Nuclear Materials Accounting Systems Modernization Initiative - U. S. DEPARTMENT OF ENERGY - JUNE 2002

9 Shultis , J. Kenneth and Faw , Richard E. - Fundamentals of Nuclear Science and Engineering - Kansas State University - Manhattan, Kansas, 
U.S.A. Marcel Dekker, Inc. - 270 Madison Avenue, New York, NY 10016, 2002

10 Mitsuo, Descrição das Células do Núcleo do Reator IEA-R1 - 1997

11 Plano de Controle de Material Nuclear - Reator IEA-R1- 2002

12 Manzano, J. A. N. G. Estudo Dirigido - Visual Basic 6 - 2004 - Editora Érica, São Paulo.

13 Perry, G. - Aprenda em 21 dias Visual Basic 6 - 1999 - Elsevier Editora, Rio de Janeiro.

14 Damy, M de A. ; Terremoto L. A. A. ; Silva, J. E. R. ; Silva, A. T. ; Teodoro, C A., Lucki, G.; Castanheira M. Acompanhamento da irradiação dos elementos combustíveis REATOR IEA-R1 - 2005 International Nuclear Atlantic Conference - INAC 2005 Santos, SP, Brazil, August 28 to September 2, 2005 ASSOCIAÇÃO BRASILEIRA DE ENERGIA NUCLEAR - ABEN ISBN: 85-99141-01-5

15 Silva, J. E. R. ; Silva, A. T. ; Terremoto, L. A. A. and Durazzo M. Program for IN-PILE qualification of high density silicide dispersion fuel at IPEN/CNEN-SP - 2009 International Nuclear Atlantic Conference - INAC 2009 Rio de Janeiro,RJ, Brazil, September 27 to October 2, 2009 ASSOCIAÇÃO BRASILEIRA DE ENERGIA NUCLEAR - ABEN ISBN: 978-85-99141-03-8

16 Maisuda, H. T., Araujo, J. A. e Floh, B. Avaliação dos produtos irradiação nos combustíveis tipo MTR do Reator IEA-R1 - 1977 - Publicação IEA 466.

17 Tondin, J. B. M. e Madi, T.F. - 2010 - Burn up and Operation Time of Nuclear Fuel Element Produced at the Nuclear and Energy Research Institute, IPEN-CNEN/SP - XXXIII Reunião de Trabalho sobre Física Nuclear no Brasil - Campos do Jordão, SP, Brasil, 7 a 11 de Setembro de 2010. 
